Revista Brasileira de Meteorologia, v.29, n.2, 209 - 228, 2014

\title{
APLICAÇÃO DE UMA FERRAMENTA OBJETIVA PARA PREVISÃO DE TEMPO SEVERO EM AMBIENTE OPERACIONAL
}

\author{
HENRI ROSSI PINHEIRO, GUSTAVO CARLOS JUAN ESCOBAR, KELEN MARTINS ANDRADE
}

Instituto Nacional de Pesquisas Espaciais (INPE), Cachoeira Paulista, SP, Brasil

henri.pinheiro@cptec.inpe.br, gustavo.escobar@cptec.inpe.br, kelen.andrade@cptec.inpe.br

Recebido Maio de 2013 - Aceito Agosto de 2013

\begin{abstract}
RESUMO
Este estudo discute a viabilidade de se empregar uma ferramenta objetiva para previsão de tempo severo em ambiente operacional, com o propósito principal de auxiliar a rotina do meteorologista previsor. O método baseia-se na combinação de parâmetros convectivos amplamente conhecidos na literatura, como os índices de instabilidade $K$, Total Totals e SWEAT. Para ajudar a identificação rápida das áreas com alto potencial para gerar tempestades foram produzidas cartas de visualização, definidas a partir de critérios específicos para convecção severa. Uma alternativa para detectar áreas favoráveis à ocorrência de granizo também foi apresentada, essencialmente para aqueles eventos originados pela ação de mecanismos dinâmicos. Os limiares mostraram-se importantes para caracterização do tipo de precipitação, permitindo através deles estabelecer diferentes padrões convectivos. Os resultados mostraram que a ferramenta proposta pode representar uma alternativa eficiente para a previsão de tempo na América do Sul, permitindo em alguns casos suprir limitações corriqueiras dos modelos numéricos, principalmente no que se refere à variável precipitação.
\end{abstract}

Palavras-chave: ferramenta objetiva, índices de instabilidade.

\begin{abstract}
APPLYING AN OBJECTIVE FORECASTING TOOL FOR SEVERE WEATHER IN OPERATIONAL ENVIRONMENT

This study discusses the feasibility of employing an objective forecasting tool in an operational environment, with main purpose of aiding the human forecaster in the task of thunderstorm prediction. The method is based on the combination of widely documented convective parameters, such as K, Total Totals and SWEAT instability indices. Charts were produced to help the identification of areas with high potential to generate storms, defined by specific criteria for severe weather. An alternative for detecting areas favorable to hail occurrence was also presented for identifying those events originated by strong dynamical forcing. The thresholds used were important to characterize the precipitation behavior, allowing them to discriminate different convective modes. The results showed that the objective tool can be an efficient alternative for thunderstorm prediction in South America because it allows the forecaster to overcome some of the limitations found in numerical models, particularly with respect to precipitation forecasting.
\end{abstract}

Keywords: objective tool, instability index.

\section{INTRODUÇÃO}

Historicamente, é de interesse dos meteorologistas a previsão da localização e intensidade das tempestades convectivas, sobretudo aquelas associadas a condições extremas, como o granizo, chuvas intensas e ventos fortes. Esse tema tem ganhado cada vez mais importância, devido à sua incontestável ameaça às atividades humanas, podendo afetar principalmente a segurança pública, agricultura, navegação aérea e setores relacionados à geração de energia.

As tempestades severas são eventos meteorológicos intensos, formadas a partir do desenvolvimento de nuvens do tipo cumulunimbus e associadas a uma massa de ar ambiente muito instável. Atualmente são encontradas diferentes definições para tempestades severas. O serviço nacional norte-americano (National Weather Service) adotou o critério proposto por 
Johns e Doswell (1992), que define uma tempestade severa como sendo o evento meteorológico capaz de gerar pelo menos um tornado, ou ventos em superfície com velocidade igual ou superior a $94 \mathrm{~km} / \mathrm{h}$, ou ainda granizo de diâmetro igual ou maior do que $1,9 \mathrm{~cm}$. Esta definição não inclui tempestades causadoras de inundações repentinas.Embora alguns países considerem a taxa de precipitação e a vulnerabilidade de uma região para enchentes como parâmetros relevantes na classificação de uma tempestade severa (Mils e Colquoun, 1998).

A intensidade e a frequência das tempestades convectivas dependem muito da região geográfica e das condições atmosféricas. Uma região conhecida pela elevada frequência de eventos meteorológicos severos é o Sudeste da América do Sul (SEAM), que abrange o centro-norte da Argentina, Uruguai, parte do Sul do Brasil e do Paraguai (Brooks et al., 2003; Salio et al., 2007; Teixeira e Satyamurty, 2007). Nesta área é comum a ocorrência de episódios de tempo severo, associados com intensa precipitação, ventos fortes, granizo e ocasionalmente eventos tornádicos. Evidências desta característica foram demonstradas em diversos estudos (Fujita, 1973; Schwarzkopf, 1982; Velasco e Fritch, 1987; Brooks et al., 2003; Zipser et al., 2006), sendo a primavera o período com maior ocorrência de sistemas capazes de provocar severidade (Guedes e Silva Dias, 1984; Nogués-Paegle, 1998; Berbery e Collini, 2000; Marcelino et al., 2004 e Salio et al., 2007). No estudo de Brooks et al. (2003) é apresentada uma estimativa global da frequência de eventos meteorológicos com potencial de provocar tempo severo e tornados, indicando um sinal nitidamente favorável sobre a região SEAM.

No Brasil, a maior incidência de eventos severos é observada nas Regiões Sul e Sudeste (Silva Dias e Grammelsbacher, 1991; Silva Dias, 2011, Marcelino et al., 2003), inclusive com registro de tornados na Região Sul (Marcelino et al., 2009). Nascimento (2005) menciona uma estatística realizada pela defesa civil do estado do Paraná, o qual revela que aproximadamente $50 \%$ dos desastres naturais registrados neste estado estão associados a episódios de tempo severo. A alta frequência de eventos severos nesta região deve-se principalmente ao escoamento atmosférico, que frequentemente se apresenta na forma do Jato de Baixos Níveis (JBN), promovendo o transporte de calor e umidade da Região Amazônica para regiões subtropicais e de latitudes médias. A relação entre a precipitação no SEAM e a intensidade do JBN é demonstrada em diversos estudos (Nogués-Paegle e Mo, 1997; Saulo et al., 2000, Marengo et al., 2002), podendo em alguns casos ser reforçada pelo deslocamento de sistemas frontais (Machado e Laurent, 2004).

A ocorrência de granizo associada a eventos severos geralmente provoca prejuízos sócio-econômicos, gerando sempre uma grande preocupação à sociedade. Os danos causados dependem de alguns fatores, como o tamanho do granizo, a velocidade de queda, a área de atuação e a duração da tempestade (Marcelino et al., 2004). Técnicas objetivas, baseadas em radares meteorológicos, têm tornado possível a previsão de tempo de curtíssimo prazo (de 2 a 6 horas) das tempestades de granizo, permitindo inclusive estimar o tamanho máximo das pedras (Witt et al., 1998; Joe et al., 2004; Brimelow et al., 2002). Como alternativa para um prognóstico de prazo maior, existem métodos que prevêem a localização da precipitação de granizo, a partir de perfis verticais estimados por modelos numéricos (Moore e Pino, 1990; Dehenauw, 2003).

Eventos severos associados à chuvas intensas também são observados em latitudes mais baixas na América do Sul, gerando muitas vezes significativos impactos sociais e econômicos à sociedade. Entre os meses de outubro e abril, a maioria das áreas tropicais e subtropicais do Brasil é dominada por um clima quente e úmido, representando mais de $90 \%$ da precipitação anual em alguns locais (Gan et al., 2004). Neste período, é comum se observar episódios de chuva intensa e persistente associados à Zona de Convergência do Atlântico Sul (Kodama, 1992; Quadro, 1994), ocasionando muitas vezes inundações e deslizamentos de terras em áreas vulneráveis. Eventos convectivos como este costumam apresentar características distintas daqueles que ocorrem em latitudes subtropicais e médias, onde a dinâmica da atmosfera desempenha um papel relevante na produção dos fenômenos de tempo. Por isso, é importante o conhecimento das características de cada região, para que sejam adotadas ferramentas específicas e adequadas para cada situação meteorológica.

Em virtude dos aspectos citados anteriormente, é natural a preocupação em se obter formas que contribuam para a previsão de eventos de precipitação, especialmente aqueles que podem gerar condições de tempo mais severas. Neste contexto, os índices de instabilidade têm permitido identificar antecipadamente regiões favoráveis ao desenvolvimento de tempestades, sendo amplamente utilizados em centro operacionais de previsão de tempo (Johns e Doswell, 1992). Estes parâmetros permitem expressar o caráter termodinâmico e cinemático da atmosfera, e podem ser obtidos a partir de perfis verticais calculados de sondagens ou derivados de modelos numéricos. Em Nascimento (2005) é feita uma ampla revisão sobre a aplicação de alguns parâmetros atmosféricos, úteis para a detecção de ambientes propícios à ocorrência de tempo severo. Nascimento (2005) discute a viabilidade em adotar estratégias, sob o ponto de vista operacional, para previsão de sistemas convectivos em diferentes regiões da América do Sul.

Atualmente, a utilização de índices de instabilidade para prognósticos tem ganhado cada vez mais importância em ambientes operacionais. Entretanto, a aplicabilidade e a interpretação de cada um destes parâmetros são dependentes 
de características específicas, como a região geográfica e o contexto sinótico. Deve-se ter em mente que o uso de um único parâmetro meteorológico para identificação de ambientes severos não representa valor significativo para previsão, sendo mais eficiente quando feita uma combinação entre eles (Doswell e Schultz, 2006). No entanto, a necessidade de se realizar um prognóstico de forma rápida, apropriado à rotina operacional, tem induzido meteorologistas previsores a tomar decisões baseadas exclusivamente em uma variável ou em um único parâmetro, como a precipitação prevista por modelos numéricos, podendo ocasionalmente levar a interpretações não realísticas.

É sabido que a maioria dos índices de instabilidade foi desenvolvida para regiões de latitudes médias no Hemisfério Norte, em condições frequentemente distintas em relação às observadas sobre a América do Sul. No Brasil, poucos esforços foram feitos para ajustar e avaliar a aplicação de índices de instabilidade para previsão de eventos convectivos. Uma exceção foi o estudo de Nascimento e Foss (2010), que usaram 12 anos de sondagens atmosféricas diárias para encontrar a distribuição mensal e anual de diversos parâmetros úteis para convecção severa. Em comparação às evidências encontradas no Hemisfério Norte, os resultados deste estudo mostraram diferenças importantes na magnitude dos parâmetros e no setor de desenvolvimento das tempestades.

Hallak e Pereira Filho (2012) ressaltam a carência de estudos de autores brasileiros que comprovem estatisticamente a eficácia dos índices de instabilidade para previsão de eventos severos. Muitos estudos, baseado em séries climatológicas, não vinculam o comportamento dos índices com a situação meteorológica (Oliveira e Oyama, 2009; Santos e Silva et al., 2011). Outros avaliaram o comportamento dos índices para casos isolados, como em Beneti e Silva Dias (1986), Fogaccia e Pereira Filho (2002) e Menezes et al. (2006), para eventos ocorridos nas cidades de São Paulo, Guarulhos e Rio de Janeiro, respectivamente.

Recentemente, uma inovadora e objetiva técnica de previsão de tempo foi apresentada por Escobar e Silva (2009), cuja metodologia baseia-se na sobreposição de variáveis e parâmetros meteorológicos. Esta ferramenta produz cartas de fácil visualização, derivadas a partir de perfis atmosféricos simulados por modelos numéricos. Os resultados deste estudo mostraram que a ferramenta automática foi capaz de identificar um evento severo no interior da Argentina, suprindo a limitação da precipitação subestimada pelo modelo. A eficácia desta ferramenta também foi demonstrada por Andrade et al. (2010), permitindo localizar com 72 horas de antecedência as áreas potencialmente favoráveis para a ocorrência de um evento severo no Rio Grande do Sul.

São raros os estudos que apresentam formas de empregar índices convectivos na rotina operacional. Para suprir esta carência, o objetivo deste estudo é propor uma metodologia capaz de identificar de forma prática e operacional, regiões com condições favoráveis à ocorrência de tempo severo, explorando a sinergia presente na combinação entre os índices de instabilidade atmosférica (Doswell e Schultz, 2006).

Neste estudo, a técnica objetiva utilizada por Escobar e Silva (2009) e descrita em Andrade et al. (2010) será avaliada com mais detalhes. O objetivo é verificar se esta metodologia é capaz de identificar condições favoráveis à ocorrência de tempo severo em diferentes situações meteorológicas. Desta forma, esta técnica será aplicada para três eventos de tempo, ocorridos em diferentes regiões da América do Sul e em condições sinóticas distintas. Será realizada uma análise sinótica de cada episódio, a fim de caracterizar o ambiente atmosférico associado a cada evento.

\section{DADOS E METODOLOGIA}

\subsection{Modelo Regional ETA/CPTEC}

Neste estudo utilizou-se os dados das análises e das previsões numéricas do modelo regional ETA(Mesinger 1984; Black, 1994), de diferenças finitas e baseado na coordenada ETA (Mesinger et al, 1988). Este modelo rodou operacionalmente no CPTEC/INPE até o início de 2012, com $20 \mathrm{~km}$ de espaçamento horizontal de grade, 38 camadas na vertical e cobrindo praticamente toda a América do Sul. O código foi desenvolvido na Universidade de Belgrado e adaptado para o esquema de convecção Betts-Miller-Janjic (Janjic, 1994). Os parâmetros convectivos calculados a partir dos perfis verticais da atmosfera e as demais variáveis meteorológicas utilizadas neste estudo foram geradas com análise do modelo ETA $20 \mathrm{~km}$ e as previsões efetuadas com tempo de integração de até 66 horas.

\subsection{Metodologia objetiva para identificação de convecção severa}

A metodologia proposta neste estudo foi desenvolvida pelo Grupo de Previsão de Tempo (GPT) do CPTEC/INPE e tem sido utilizada operacionalmente para a previsão de tempo severo. A ferramenta objetiva produz cartas para visualização, que são geradas a partir do "software" GrADS. Estas cartas agregam diversas informações relevantes para previsão de ambientes convectivos, a partir da combinação entre o conteúdo de umidade na camada baixa e média e os índices de instabilidade $K$, Total Totals (TTS) e Severe Weather Threat (SWEAT). Estes parâmetros refletem diversos aspectos da convecção, sendo muito eficientes para previsão de episódios de tempo severo quando agrupados entre si (Doswell e Schultz, 2006). 
Existem outros parâmetros convectivos não utilizados neste estudo, mas que também apresentam estimável valor para previsão de tempo (severo ou não), tais como, o lifted e o CAPE. Análises destes índices geradas a partir da saída de modelos numéricos é um recurso muito usado em ambientes operacionais (Galway, 1956; Houze et al., 1993), porém os parâmetros citados não foram incluídos neste estudo devido a sua maior dificuldade para a implementação.

A caracterização do estágio de severidade é determinada a partir da atribuição de diferentes limiares para os índices de instabilidade K, TTS e SWEAT. A combinação entre cada índice resulta em cartas de visualização, utilizadas essencialmente para identificar padrões atmosféricos associados à "pancadas de chuva com trovoadas", "tempestades" e "granizo". Os critérios usados nas duas primeiras cartas são bastante semelhantes, sendo muito úteis para identificar precipitação intensa. Neste caso, a termodinâmica tem um papel relevante para o desenvolvimento da convecção, que eventualmente pode estar associado à combinação entre a presença de umidade e o forte aquecimento em superfície. Por outro lado, a carta granizo foi desenvolvida para identificar ambientes favoráveis à ocorrência de tempestades mais severas, que apresentam maior cisalhamento vertical e correntes ascendentes suficientemente intensas para gerar granizo. Desta forma, a componente dinâmica passa a ter uma contribuição maior para a geração das tempestades. Detalhes dos critérios empregados em cada carta são discutidos na seção 2.2.2.

Para avaliação da ferramenta objetiva foram analisados três situações meteorológicas distintas, utilizando imagens de satélite e de radar (este último apenas para os casos disponíveis). A análise numérica do modelo regional ETA foi utilizada para caracterização da situação sinótica e avaliação da previsão do modelo.

\subsection{1 Índices de Instabilidade}

$\mathrm{O}$ índice $\mathrm{K}$ pode ser usado como indicativo para ocorrência de tempestades e seu cálculo baseia-se na taxa vertical de temperatura, no conteúdo de umidade na baixa troposfera e na extensão da camada úmida. Valores acima de 30 são considerados relevantes para tempestades e acima de 40 representam alto risco para ocorrência de tempestades severas. Entretanto, a utilização deste índice merece uma ressalva na sua interpretação, pois algumas tempestades severas podem ocorrer com valores relativamente baixos de $\mathrm{K}$, devido à intrusão de ar seco na camada baixa e média, resultando em um aumento da depressão do bulbo úmido em $700 \mathrm{hPa}$ (Nascimento, 2005), Esta característica costuma ser observada principalmente nas latitudes subtropicais e médias.

Este índice pode ser definido da seguinte forma (George, 1960):

$$
\mathrm{K}=\left[\mathrm{T}_{850 \mathrm{hPa}}-\mathrm{T}_{500 \mathrm{hPa}}\right]+\mathrm{Td}_{850 \mathrm{hPa}}-\left[\mathrm{T}_{700 \mathrm{hPa}}-\mathrm{Td}_{700 \mathrm{hPa}}\right]
$$

onde $T$ e $T d$ representam a temperatura e a temperatura do ponto de orvalho nos respectivos níveis de pressão.

O índice Total Totals (TTS) é a soma de dois índices de instabilidade: o Vertical Totals (VT), dado pelo lapse rate entre os níveis 850 e $500 \mathrm{hPa}$; e o Cross Totals(CT), dado pela diferença do conteúdo de umidade em $850 \mathrm{hPa}$ e a temperatura em $500 \mathrm{hPa}$. A sua aplicação é útil para avaliar o entranhamento de ar frio na troposfera média, sendo relevante para previsão de eventos severos associados à queda de granizo. Valores acima de 45 são favoráveis à ocorrência de tempestades. O índice TTS é expresso da seguinte forma (Miller, 1972):

$$
\mathrm{TTS}=\left[\mathrm{T}_{850 \mathrm{hPa}}+\mathrm{Td}_{850 \mathrm{hPa}}\right]-2 \mathrm{~T}_{500 \mathrm{hPa}}
$$

O índice SWEAT combina diversos parâmetros importantes, agregando as componentes dinâmica e termodinâmica da atmosfera. Foi desenvolvido por Miller (1972) e adaptado para o Hemisfério Sul. Valores maiores do que 250 representam significativa possibilidade de tormentas, sendo consideradas apenas as contribuições positivas na expressão abaixo:

SWEAT $=12 \mathrm{Td}_{850 \mathrm{hPa}}+20(\mathrm{TTS}-49)+2 \mathrm{~V}_{850 \mathrm{hPa}}+\mathrm{V}_{500 \mathrm{hPa}}$ $+125($ cis $+0,2)$

onde $\mathrm{V}_{850 \mathrm{hPa}}$ e $\mathrm{V}_{500 \mathrm{hPa}}$ são a velocidade do vento em nós em $850 \mathrm{hPa}$ e $500 \mathrm{hPa}$, respectivamente;

$$
\text { cis }=\operatorname{sen}\left[\text { direção (graus) } \mathrm{V}_{500 \mathrm{hPa}}-\mathrm{V}_{850 \mathrm{hPa}}\right]
$$

\subsubsection{Descrição do Método Automático}

Os limiares utilizados em cada carta a seguir foram escolhidos a partir de valores de referência encontrados na literatura (Beneti e Silva Dias, 1986; Henry, 1987; Silva Dias, 2000; Nascimento, 2005, Escobar e Andrade, 2010) e baseados na experiência operacional dos meteorologistas previsores do GPT, sendo válidos essencialmente para regiões subtropicais e médias da América do Sul. Os limiares utilizados pelo GPT foram definidos empiricamente a partir de estudo de casos utilizando dados de reanálises, radiossondagens e modelos numéricos de previsão de tempo. Além disso, agrega-se a ampla experiência prática dos autores, que reconhecem existir limitações em atribuir faixa de valores específicos para discriminar diferentes estágios de convecção, sem a realização prévia de um estudo estatístico. A extensão territorial da área de interesse para previsão de tempo no Brasil e na América do Sul requer critérios para deteç̧ão de eventos convectivos que se enquadrem à maioria das regiões de interesse. Lembrando que o Brasil é um país com dimensões continentais, com regiões que apresentam diferentes características climatológicas. 
Os estágios de severidade e os critérios utilizados em cada carta de tempo são descritos a seguir:

i. Carta - Pancada de chuva por calor e umidade: adequada para identificar precipitação convectiva, porém não necessariamente intensa e bem distribuída. O critério inclui uma combinação entre os índices de instabilidade K (superior a 30) e TTS (superior a 45). Nesta carta ainda são plotadas os ventos em $250 \mathrm{hPa}$ maiores do que $20 \mathrm{~m} / \mathrm{s}$ e em $850 \mathrm{hPa}$ maiores do que $10 \mathrm{~m} / \mathrm{s}$.

ii. Carta - Pancada de Chuva com Trovoada: o objetivo desta carta é identificar chuvas geralmente moderadas ou intensas e acompanhadas de atividade elétrica. Neste caso, leva-se em consideração a combinação das seguintes variáveis: umidade relativa média nas camadas 1000/850 hPa e 850/500 $\mathrm{hPa}$ acima de 60\%; omega em $500 \mathrm{hPa}$ negativo e inferior a $-0,05 \mathrm{~Pa} / \mathrm{s} ;$ TTS $>45$ e $\mathrm{K}>30$.

iii. Carta - Tempestade: o objetivo desta carta é identificar a ocorrência de tempo mais severo, geralmente associado com chuvas torrenciais, rajadas de vento, abundantes descargas elétricas e até presença de tornados. Neste caso, o critério é idêntico à carta anterior (ii), porém com limiares mais restritivos de TTS (TTS $>48)$ e $K(K>33)$.

iv. Carta - Granizo: esta carta tem como intuito identificar prováveis áreas com potencial para ocorrência de granizo, através do seguinte critério: omega negativo em $500 \mathrm{hPa}$ inferior a $-0,05 \mathrm{~Pa} / \mathrm{s}$; umidade relativa média nas camadas $1000 / 850$ $\mathrm{hPa}$ e 850/500 hPa acima de 60\%; SWEAT > 220 e TTS $>52$. Silva Dias (2000) sugere como condição para tempestades com granizo valores de TTS superiores a 50, enquanto o índice $\mathrm{K}$ pode apresentar valores não necessariamente elevados. É plotado também nesta carta a temperatura no nível de $500 \mathrm{hPa}$ e os valores negativos de omega em $500 \mathrm{hPa}(\mathrm{Pa} / \mathrm{s})$ inferiores a $-0.3 \mathrm{~Pa} / \mathrm{s}$. Vale ressaltar que esta carta não foi desenvolvida para o uso específico de previsão de vendavais, no qual a umidade moderadamente alta em toda a média troposfera pode desfavorecer as tempestades geradoras de ventos intensos (Wakimoto, 2001). Os autores já observaram tempestades acompanhadas de granizo com elevada umidade relativa do ar na camada média, inclusive com valores de $\mathrm{K}$ acima de 35 . Esta característica se observa com mais frequência em latitudes subtropicais ou em ambientes com características tropicais. Os autores reconhecem as limitações desta carta e a necessidade de melhorias futuras.

Nas cartas descritas acima, cada ponto de grade do modelo é hachurado toda vez que satisfazer o limiar definido para cada parâmetro convectivo. Desta forma, uma área sombreada aparecerá sempre que houver condições para pancadas de chuva por calor e umidade, pancadas de chuva com trovoadas, tempestade e/ou granizo. Na seção 3 deste trabalho serão apresentados os resultados da aplicação desta ferramenta para três episódios de tempo severo. Estes eventos foram escolhidos por apresentarem padrões sinóticos distintos, sendo que dois destes ocorreram no território brasileiro e um na Argentina.

\section{RESULTADOS}

\subsection{Tempestade tornádica em Buenos Aires: caso 1}

\subsubsection{Descrição do evento}

Este evento meteorológico ocorreu entre a tarde e o começo da noite do dia 4 de abril de 2012 e foi escolhido por ser considerado um evento severo, pois causou muita destruição e 17 mortes na Argentina (16 na Região Metropolitana de Buenos Aires). As tormentas mais severas atingiram a capital federal, provocando chuva intensa, queda de granizo e intensas rajadas de vento. O Serviço Meteorológico Nacional da Argentina (SMN) analisou os danos causados e classificou o caso como um evento severo, com ocorrência de tornado de categoria F2 na escala Fujita (que abrange ventos entre 180 e $250 \mathrm{~km} / \mathrm{h}$ ).

A imagem do satélite GOES12 do dia 05/04/2012 às 00:00 UTC mostra um intenso Sistema Convectivo de Mesoescala (SCM), localizado sobre a Foz da Bacia do Prata (Figura 1b). Embebido nesse sistema, formou-se uma linha de instabilidade do tipo Bow Echo (Fujita, 1979), que se deslocou com orientação sudoeste-nordeste, produzindo intensas tormentas sobre a faixa norte da Província de Buenos Aires (Figura 1c). A sondagem de Ezeiza (Figura 1d) mostra um perfil muito instável, com forte advecção de ar quente e intenso cisalhamento vertical do vento nas camadas mais baixas, perfil típico de tempestades severas. Esta sondagem foi escolhida por representar a observação mais próxima e anterior ao horário do evento convectivo, no entanto, é provável que estas características tenham sido modificadas em relação ao perfil imediatamente anterior ao início do evento.

A análise sinótica da carta de superfície da 00:00 UTC do dia 05/04/2012 (Figura 1a) mostra a presença de um sistema frontal próximo à Bacia do Prata. Este sistema teve o suporte dinâmico de um cavado baroclínico em altitude (Figura $2 b)$, que se amplificou sobre o continente sul-americano e gerou forte difluência sobre o lado equatorial do Jato Polar. Esta difluência no escoamento favoreceu a divergência em altitude, contribuindo para a intensificação da convergência em superfície. Ressalta-se que esta divergência pode ser resultado também da intensa atividade convectiva.

\subsubsection{Avaliação subjetiva do método automático}

As cartas produzidas pelo método automático (Figuras 2b-2d), com a análise do modelo inicializada a 00:00 UTC do dia 05/04/2012, mostram as áreas de maior severidade, 


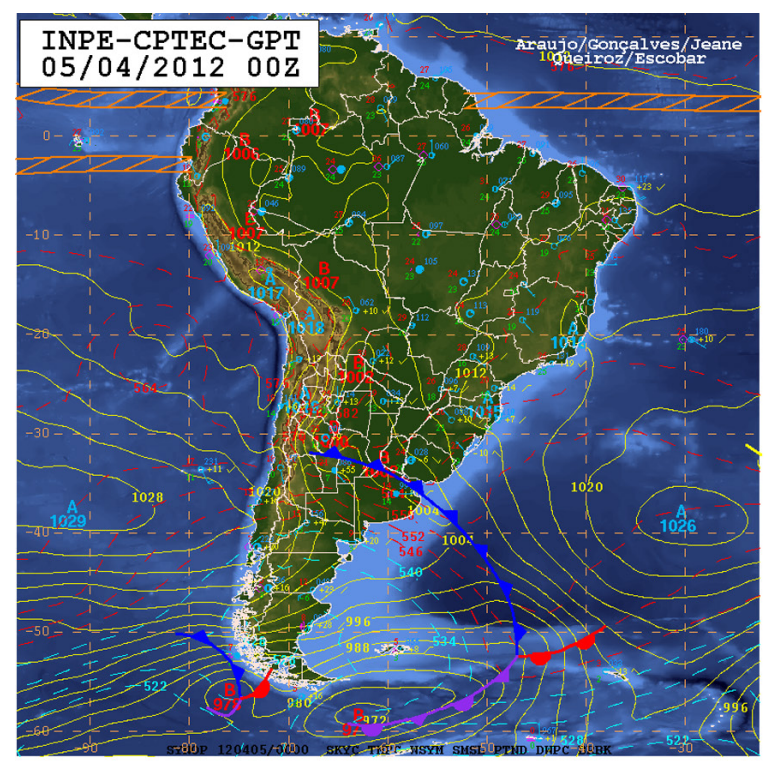

(a)



(c)

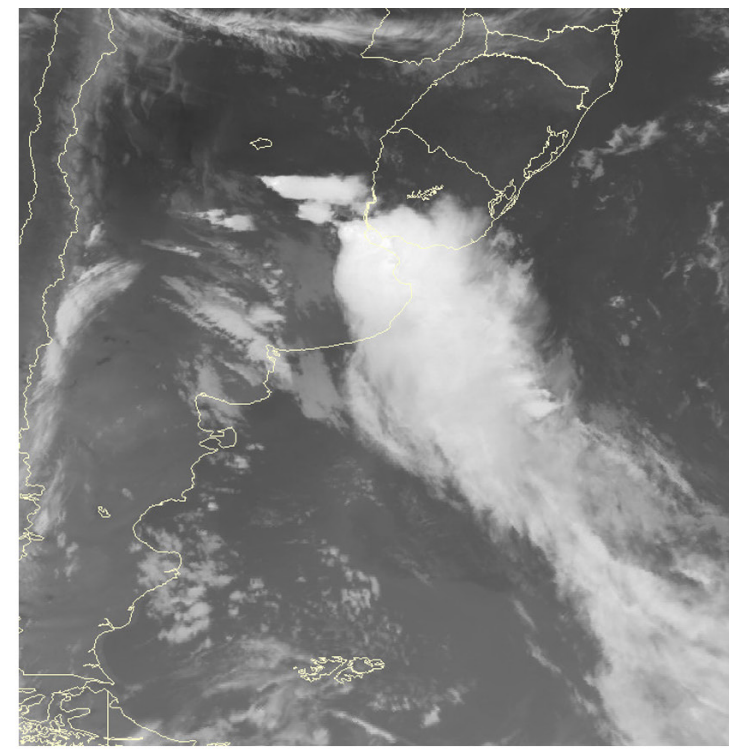

(b)

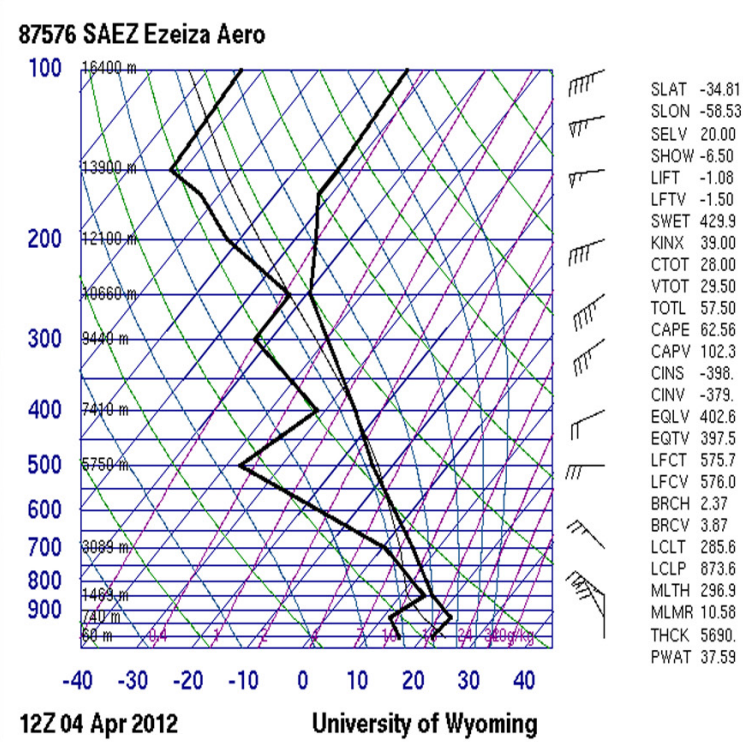

(d)

Figura 1 - (a) Carta sinótica de superfície (00 UTC - 05/04), (b) Imagem do satélite GOES-12 no canal infravermelho (00 UTC - 05/04), (b) radar meteorológico de Ezeiza/Buenos Aires (23:50 UTC - 04/05) e (c) sondagem de Ezeiza (12 UTC - 04/05/2012). Fonte da imagem de radar: Serviço Meteorológico Nacional (Argentina).

determinadas a partir dos critérios propostos na seção 2.2.2. Nota-se que a carta tempestade (Figura 2c), gerada pela análise do modelo, reproduz a área de prováveis tempestades, geradas pela aplicação do método sobre as análises do modelo, e é qualitativamente semelhante à área atingida pelo SCM, que abrange as Províncias argentinas de Buenos Aires, Entre Rios, Santa Fé e Córdoba. Nesta carta foram inclusos elementos importantes para a convecção severa, como a disponibilidade de umidade, presença de movimento ascendente em 500 hPa e valores relevantes dos índices K e TTS. Neste caso, a distribuição das áreas sombreadas em cada uma das três cartas (Figuras 2b-2d) apresentam-se bastante semelhantes, apesar dos critérios serem mais restritivos nas cartas de tempestade e granizo. Os resultados do critério "tempestade" para a previsão de 48 horas de antecedência (Figura $4 c$ ) foi qualitativamente mais adequado do que a mesma carta para a análise (Figura 


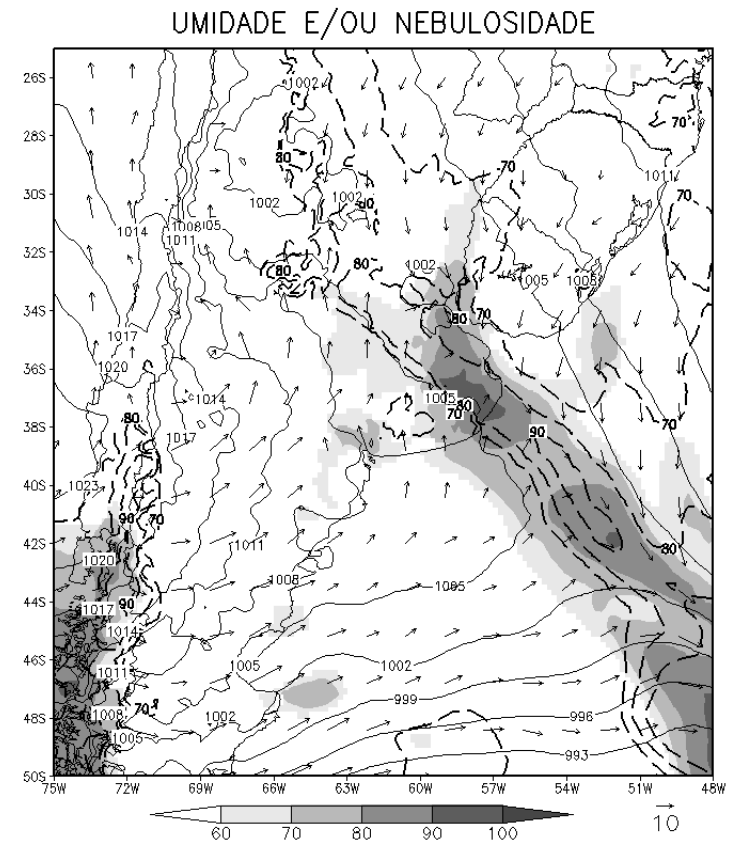

(a)

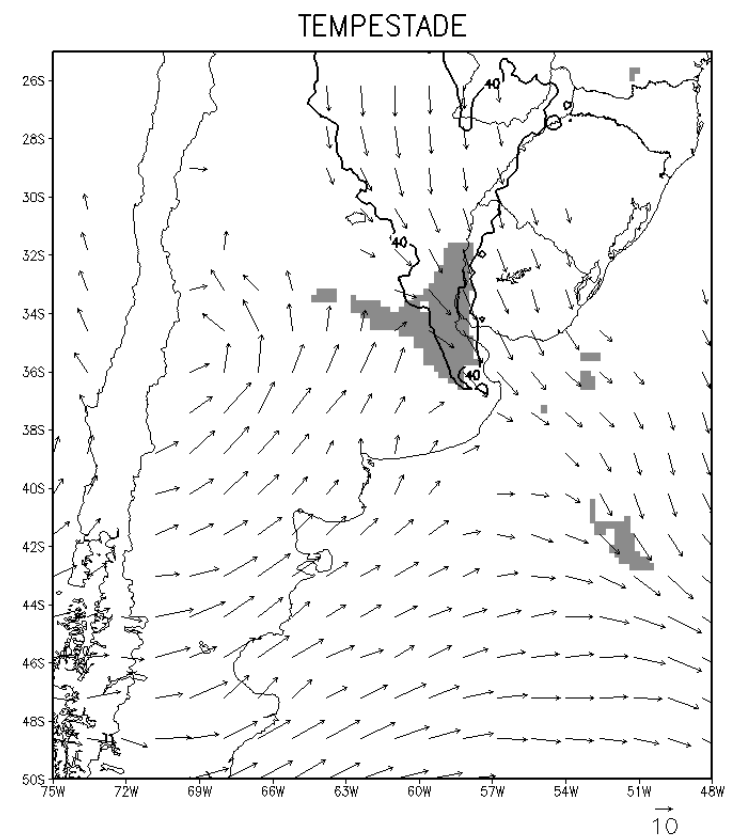

(c)

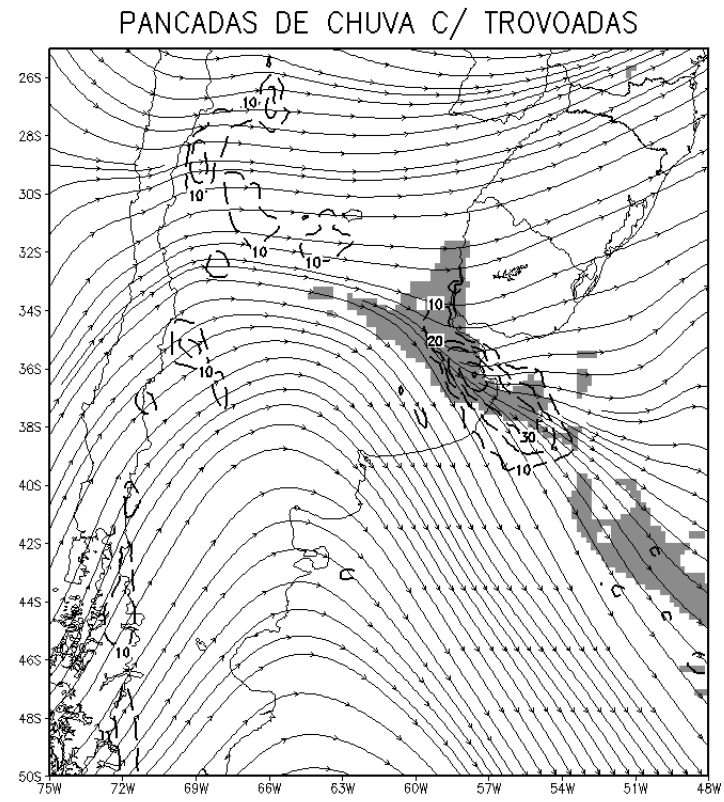

(b)

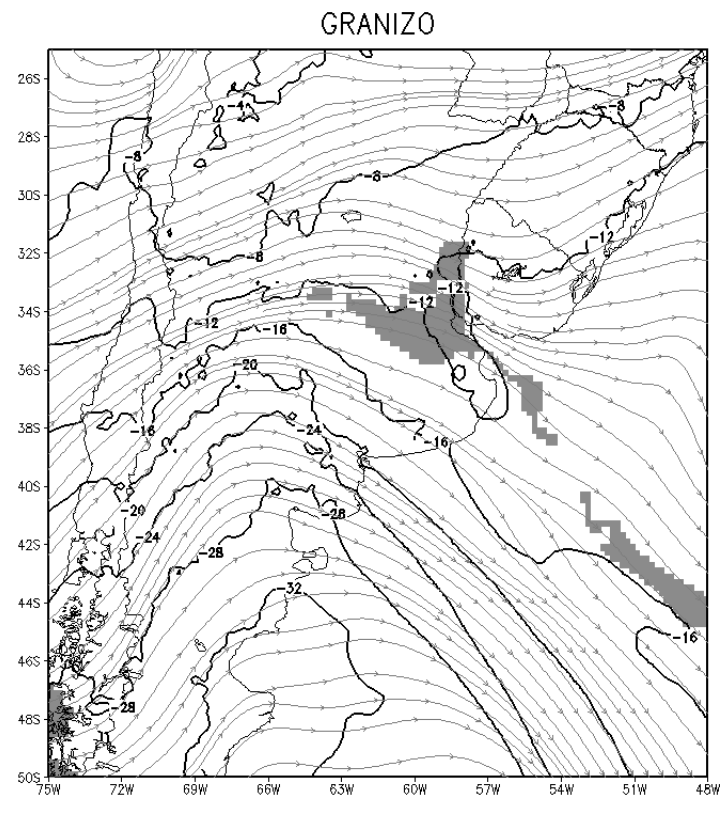

(d)

Figura 2 - Cartas geradas pela análise do modelo ETA para 00Z de 05/04/2012: (a) umidade e/ou nebulosidade, (b) pancadas de chuva com trovoadas, (c) tempestade e (d) granizo.

2c). Neste prazo, as cartas pancadas de chuva com trovoadas, tempestade e granizo permitem localizar a região mais atingida pelas tormentas. Estas áreas preferenciais aparecem ligeiramente deslocadas para norte na previsão de 24 horas (Figura 3). Do ponto de vista sinótico, essa mudança deve-se à configuração do cavado em $250 \mathrm{hPa}$ e ao posicionamento da convergência em $850 \mathrm{hPa}$, que aparecem defasados em relação à análise. A diferença entre as previsões para os prazos de 24 e 48 horas está relacionada exclusivamente ao modelo numérico ETA $20 \mathrm{~km}$ e não à ferramenta objetiva. Estudos baseados na avaliação do comportamento deste modelo para a América do Sul mostram que o índice de acerto para os prazos de $48 \mathrm{e}$ 


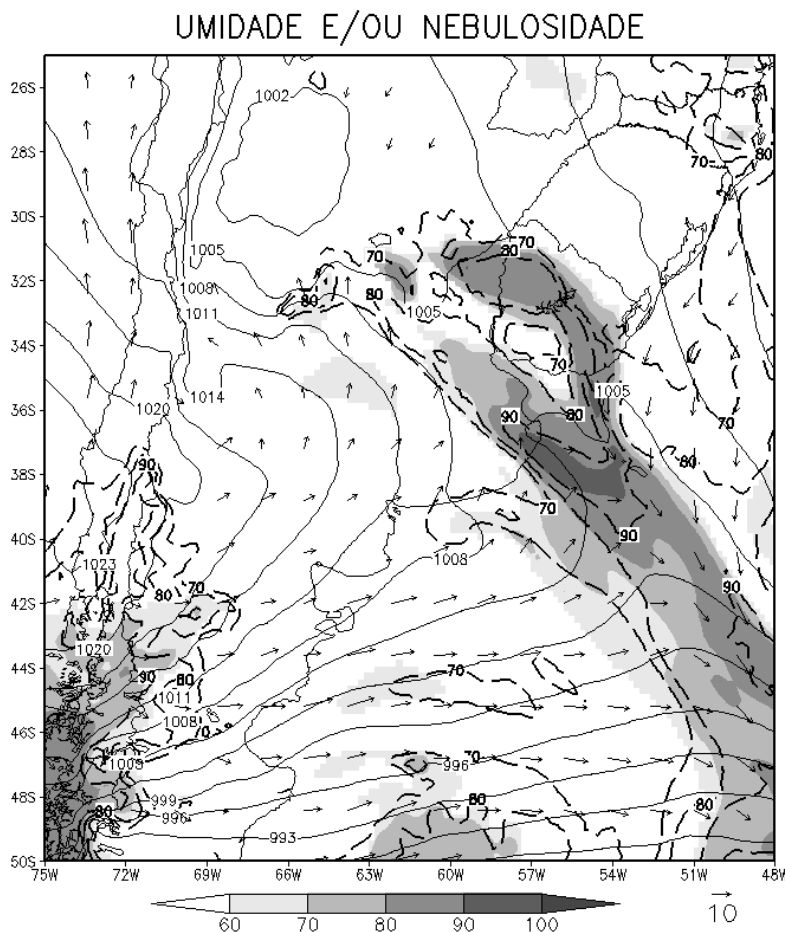

(a)

TEMPESTADE

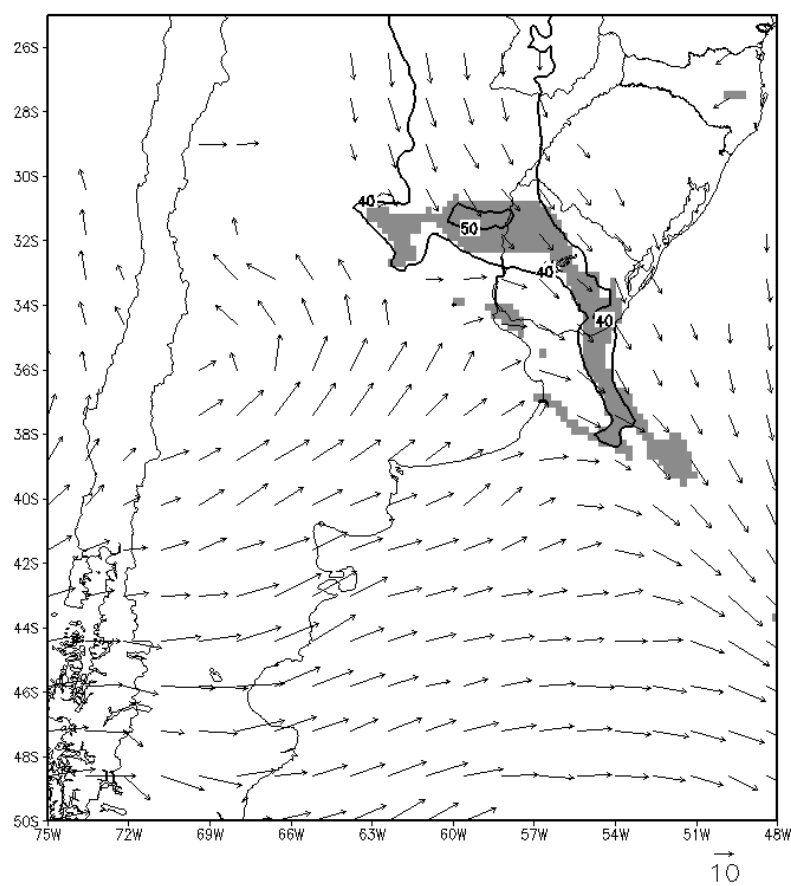

(c)

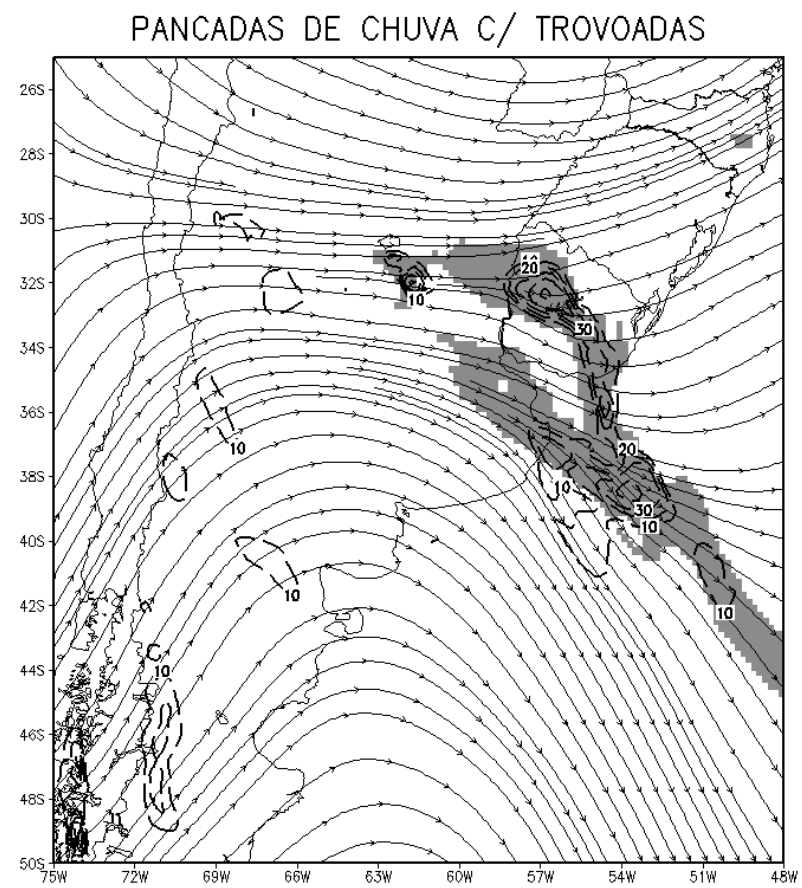

(b)

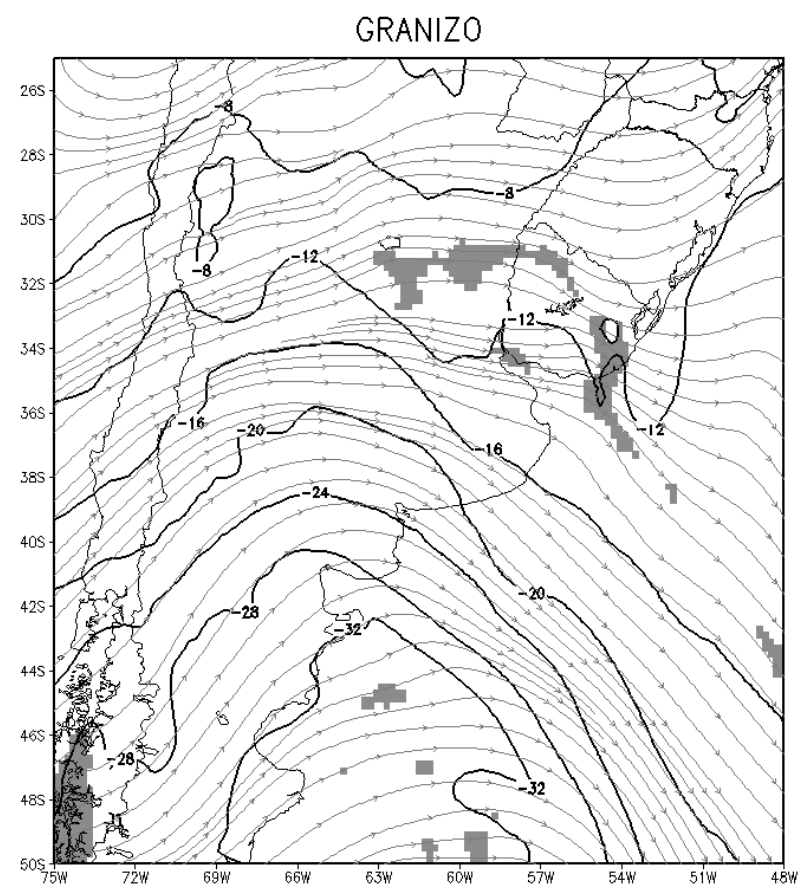

(d)

Figura 3 - Cartas previstas pelo modelo ETA com 24 horas para 00Z de 05/04/2012: (a) umidade e/ou nebulosidade, (b) pancadas de chuva com trovoadas, (c) tempestade e (d) granizo. 


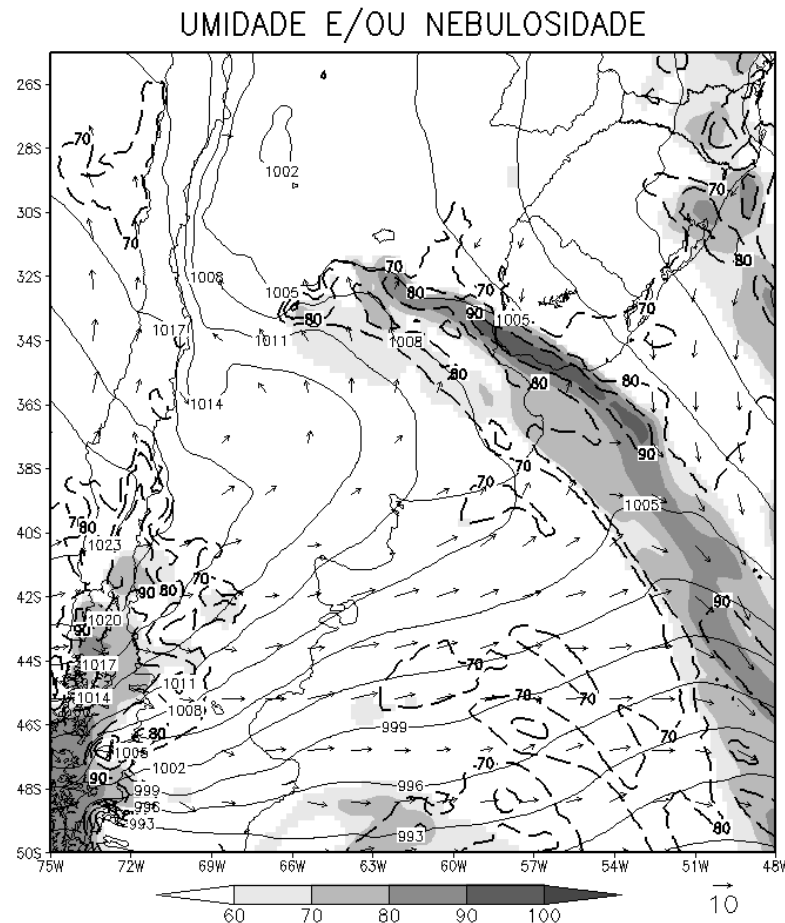

(a)

\section{TEMPESTADE}

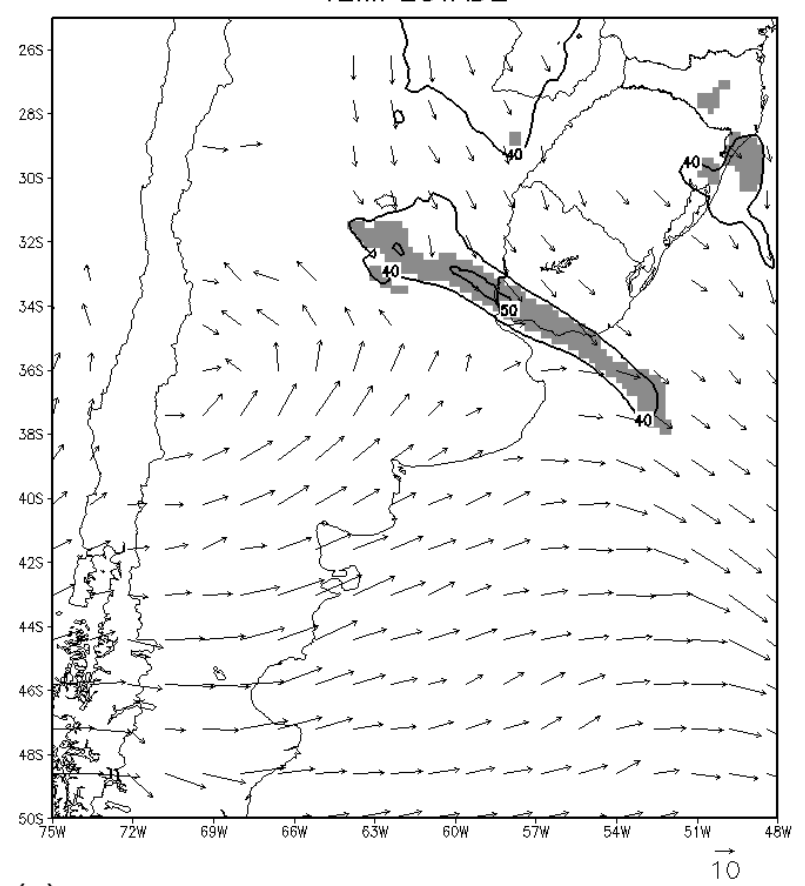

(c)

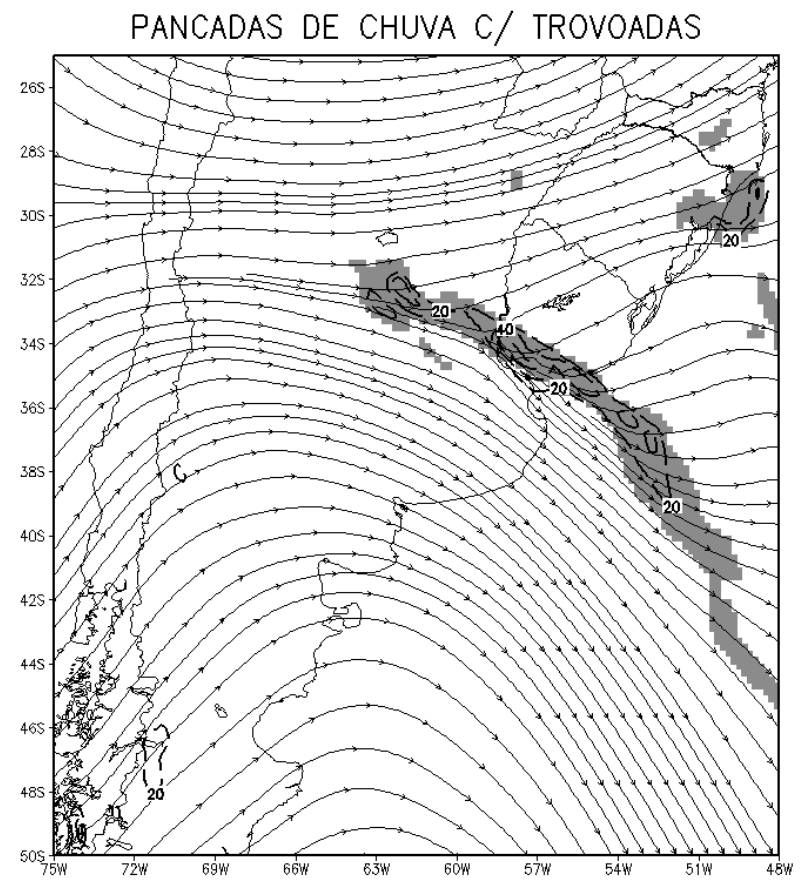

(b)

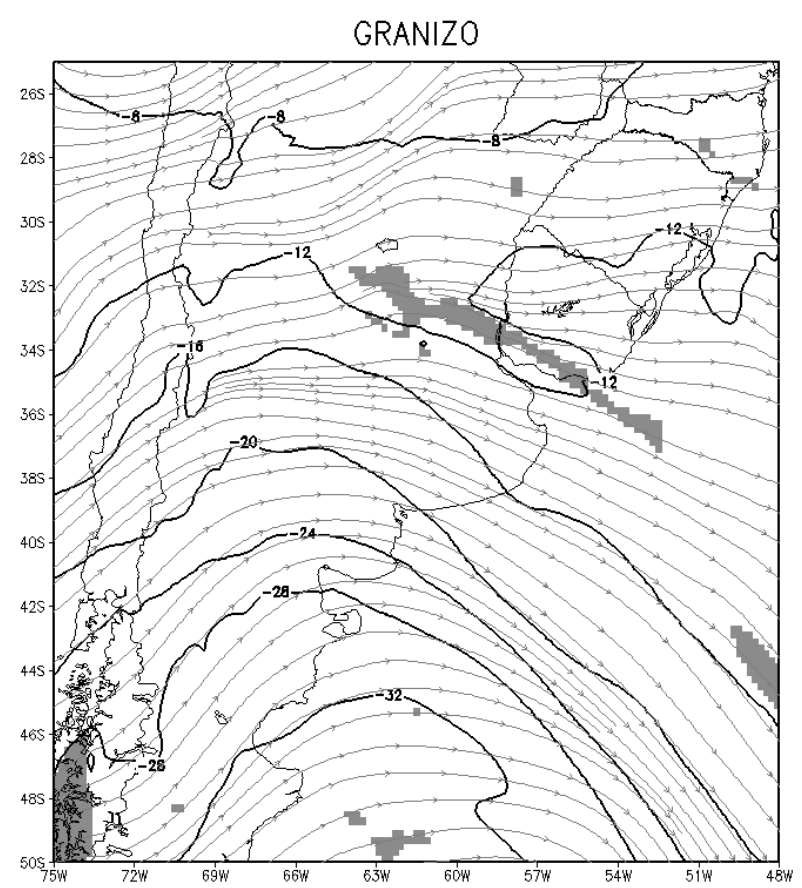

(d)

Figura 4 - Cartas previstas pelo modelo ETA com 48 horas para 00Z de 05/04/2012: (a) umidade e/ou nebulosidade, (b) pancadas de chuva com trovoadas, (c) tempestade e (d) granizo. 
72 horas costuma ser maior do que com 24 horas (Moura et. al 2010). As avaliações períodicas do desempenho do modelo ETA $20 \mathrm{~km}$ podem ser encontradas na página do CPTEC (http:// avaliacaodemodelos.cptec.inpe.br/).

\subsection{Tempestades de granizo: caso 2}

\subsubsection{Descrição do evento}

A ocorrência de episódios de tempo severo com granizo não é tão rara no Brasil, em especial na Região Sul (Marcelino et al., 2004). Os prejuízos causados por eventos deste tipo justificam a necessidade de se obter formas que auxiliem a previsão deste fenômeno. O segundo evento meteorológico foi escolhido com o propósito de avaliar a previsibilidade da ferramenta objetiva na identificação de áreas com potencial para gerar granizo. As tempestades de granizo ocorreram na tarde do dia 9 de abril de 2011 e atingiram áreas isoladas de cinco estados brasileiros: Santa Catarina, Paraná, São Paulo, Minas Gerais e Rio de Janeiro. Pelo menos 18 municípios do interior de São Paulo registraram o fenômeno.

A imagem do satélite GOES-12 no canal infravermelho às 18:15 UTC de 09/04/2011 (Figura 5a) mostra intensa atividade convectiva sobre algumas áreas destes estados, favorecidas pela presença de um vórtice ciclônico na troposfera média (Figura 5d). O ar frio em médios e altos níveis, associado ao núcleo deste sistema, foi o elemento determinante para intensificar a atividade convectiva no seu interior. A Figura 5c mostra a presença de um cavado invertido em superfície, localizado a leste entre os estados do Rio Grande do Sul e de Santa Catarina.. A sondagem de Campo de Marte em São Paulo (SP) da 00:00 UTC do dia 10/04/2011 indica valor em torno de $28^{\circ} \mathrm{C}$ para o Vertical Totals e em inferior a $-2^{\circ} \mathrm{C}$ para lifted (Figura 5b), ou seja, um perfil bastante instável considerando o aquecimento diurno observado neste dia. Uma descrição sinótica deste evento pode ser encontrada em Escobar e Silva (2012).

\subsubsection{Avaliação subjetiva do método automático}

Para avaliar a habilidade do método em identificar as áreas atingidas pelo granizo, foram geradas previsões da "carta granizo" para as 18:00 UTC (15h local) do dia 09/04/2011, aproximadamente o período em que foram registrados os temporais. Do ponto de vista sinótico, percebe-se que o posicionamento e a configuração do Vórtice Ciclônico em 500 $\mathrm{hPa}$ (Figura 6a-6c) foram bem previstos pelo modelo, exceto na previsão com 66 horas de antecedência, que mostra um cavado. A Figura 6a mostra que na previsão de 18 horas, a ferramenta indicou condições para a ocorrência de granizo sobre pontos isolados dos estados que tiveram o registro do fenômeno. Um aspecto interessante refere-se ao fato do modelo não prever chuva (Figura 7) sobre algumas áreas que foram atingidas pelo granizo e previstas pela ferramenta automática (Figura 6a). Esse resultado ressalta a importância da ferramenta para o prognóstico de eventos como este, que teve êxito ao mostrar a possibilidade para a ocorrência de granizo, mesmo em áreas onde a precipitação não foi prevista pelo modelo, como pode ser observado na Figura 7.

O centro do vórtice deixa de ser previsto a partir de 66 horas (Figura 6c), ao indicar um cavado inclinado em direção ao Paraguai e Mato Grosso do Sul. Esta alteração foi suficiente para modificar a distribuição dos índices TTS e SWEAT (figuras não mostrada), comprometendo a previsão a partir desta rodada. Esse resultado mostra que a confiabilidade da ferramenta automática depende muito da capacidade do modelo em simular o escoamento de larga escala e o perfil atmosférico.

No âmbito operacional, é importante ter em mente as limitações atribuídas à ferramenta automática, que podem conduzir a interpretações inadequadas, caso o contexto sinótico não seja analisado. Existem padrões atmosféricos associados à ocorrência de granizo que podem ser facilmente reconhecidos pelo meteorologista previsor. Uma situação comum é quando há a presença de um vórtice ciclônico de ar frio na troposfera média, semelhante ao evento analisado. Resultados de estudos confirmam que o padrão atmosférico observado revela um modelo conceitual típico para a ocorrência de granizo (Morrison e Businger, 2001; Otkin e Martin, 2004). O reconhecimento de padrões semelhantes auxilia o prognóstico, permitindo ao meteorologista operacional antecipar-se na decisão de emitir um aviso meteorológico.

\subsection{Atmosfera barotrópica: caso 3}

\subsubsection{Descrição da situação meteorológica}

O terceiro caso mostra uma situação característica de regiões tropicais da América do Sul, especificamente aquelas que apresentam um verão quente e úmido, com elevados índices pluviométricos. A sequência de imagens do satélite GOES-12 no canal infravermelho do dia 17/02/2008 às 18:00 UTC e 23:45 UTC (Figuras 8a e 8b, respectivamente) representa o período auge do ciclo diurno da convecção e a nebulosidade se distribuindo do Sudeste ao Norte do Brasil, abrangendo também parte das Regiões Centro-Oeste e Nordeste do país, assim como os países vizinhos. Este evento foi escolhido por diferenciar-se dos anteriores, uma vez que neste caso a componente termodinâmica assume o principal papel para a formação das chuvas. Nota-se que a característica da precipitação obedece um regime do tipo barotrópico de 


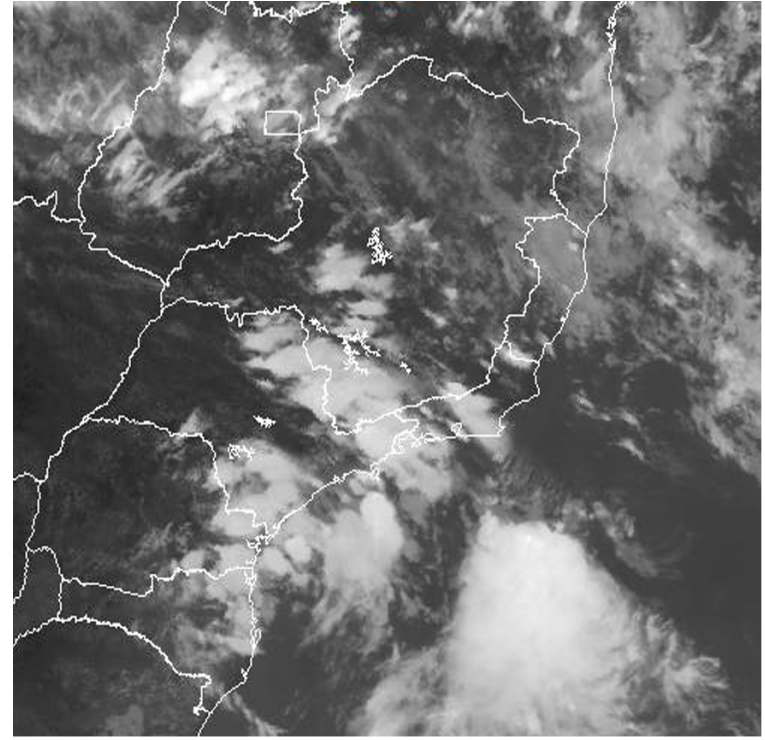

(a)

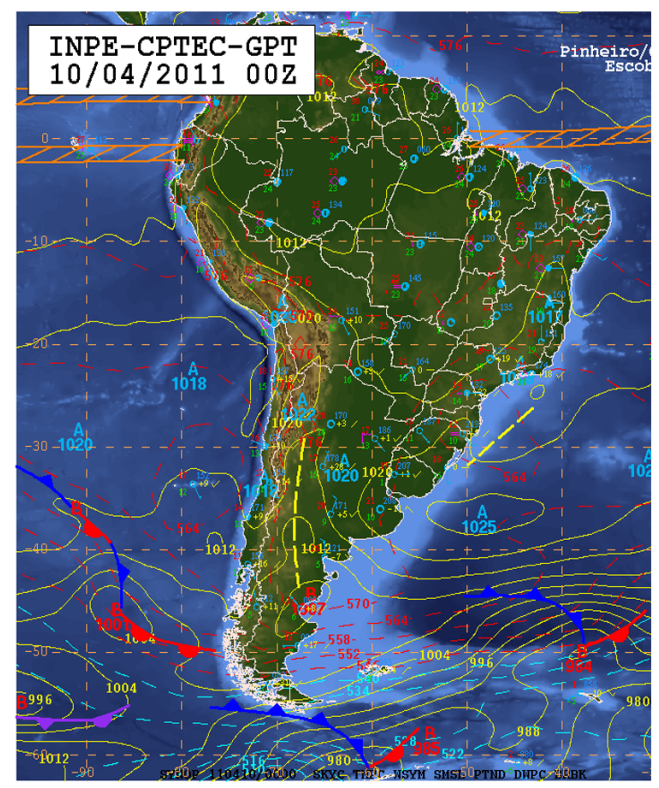

(c)
83779 SBMT Marte Civ

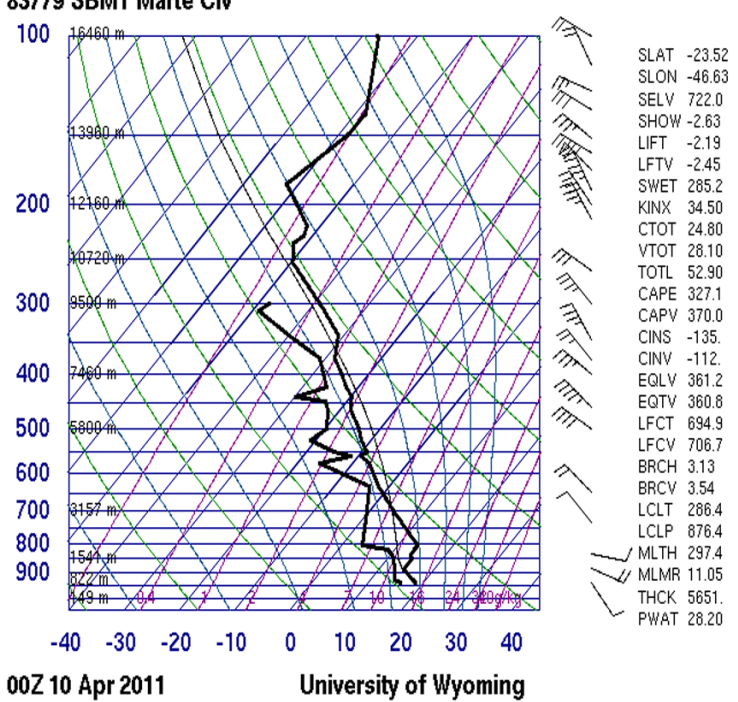

(b)

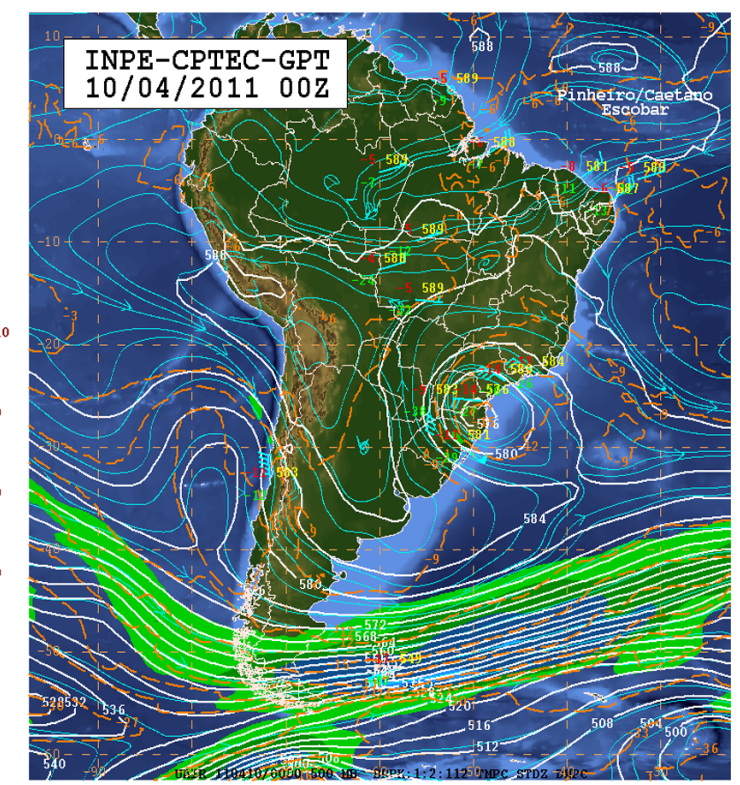

(d)

Figura 5 - (a) imagem do satélite GOES-12 no infravermelho para as 18:15 UTC de 09/04/11, (b) sondagem da 00 UTC de 10/04/11 do aeroporto de Campo de Marte (SP), cartas sinóticas de (c) superfície e de (d) 500hPa para 00 UTC de 10/04/2011.

latitudes baixas, onde as áreas convectivas distribuem-se de maneira não homogênea. A carta sinótica de altitude do dia 18/02/2008 às 00:00 UTC (Figura 8d) mostra um padrão típico de verão, com a Alta da Bolívia ligeiramente deslocada para sul em relação à sua posição climatológica e o vórtice ciclônico do Nordeste próximo da costa leste desta Região. Em superfície não há nenhum sistema meteorológico ao norte de $40^{\circ} \mathrm{S}$, sendo o continente dominado pela presença de áreas de baixa pressão (Figura 8c).

\subsubsection{Avaliação subjetiva do método automático}

Para avaliar a previsibilidade da ferramenta objetiva para o caso 3 serão acrescentadas mais duas cartas. A primeira (Figura 9a) mostra o campo de pressão ao nível médio do mar e a umidade relativa do ar média entre 1000-850 hPa e 850-500 hPa.. A carta pancadas de chuva por calor e umidade (Figura 9b) foi desenvolvida para identificar áreas com alta chance para a ocorrência de precipitação convectiva, porém 


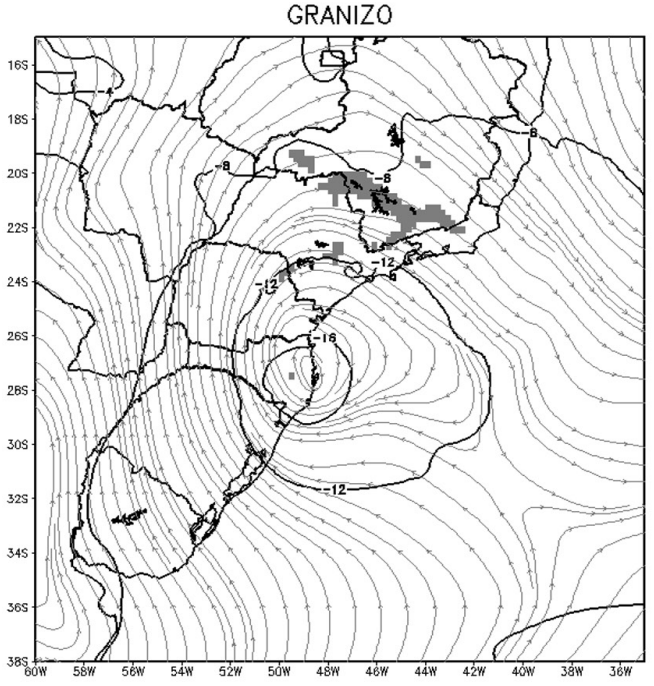

(a)

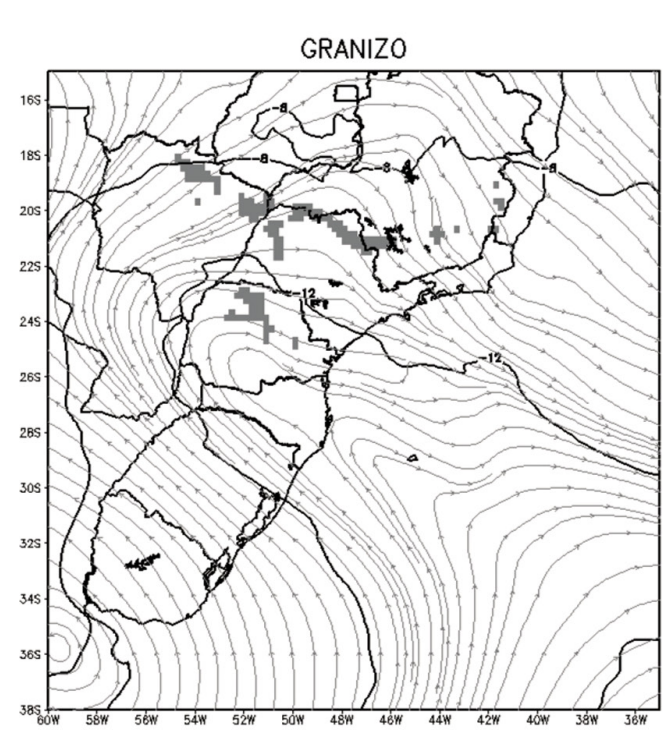

(c)

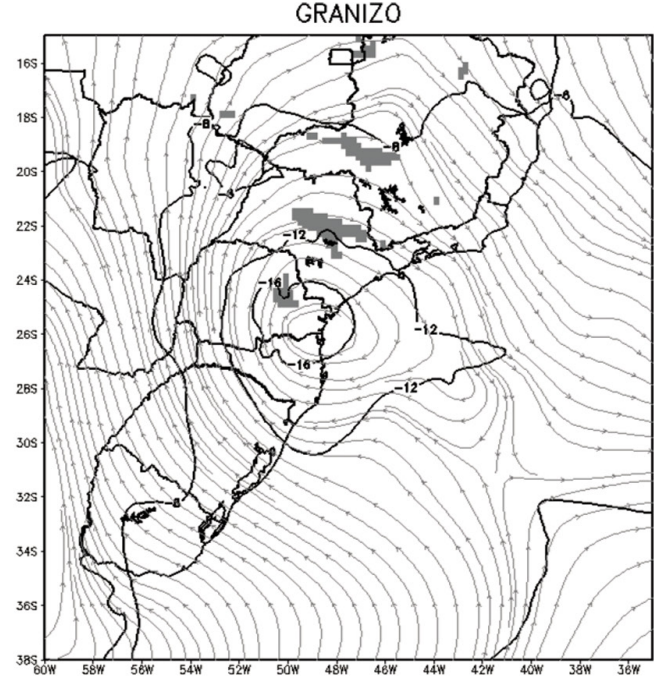

(b) 


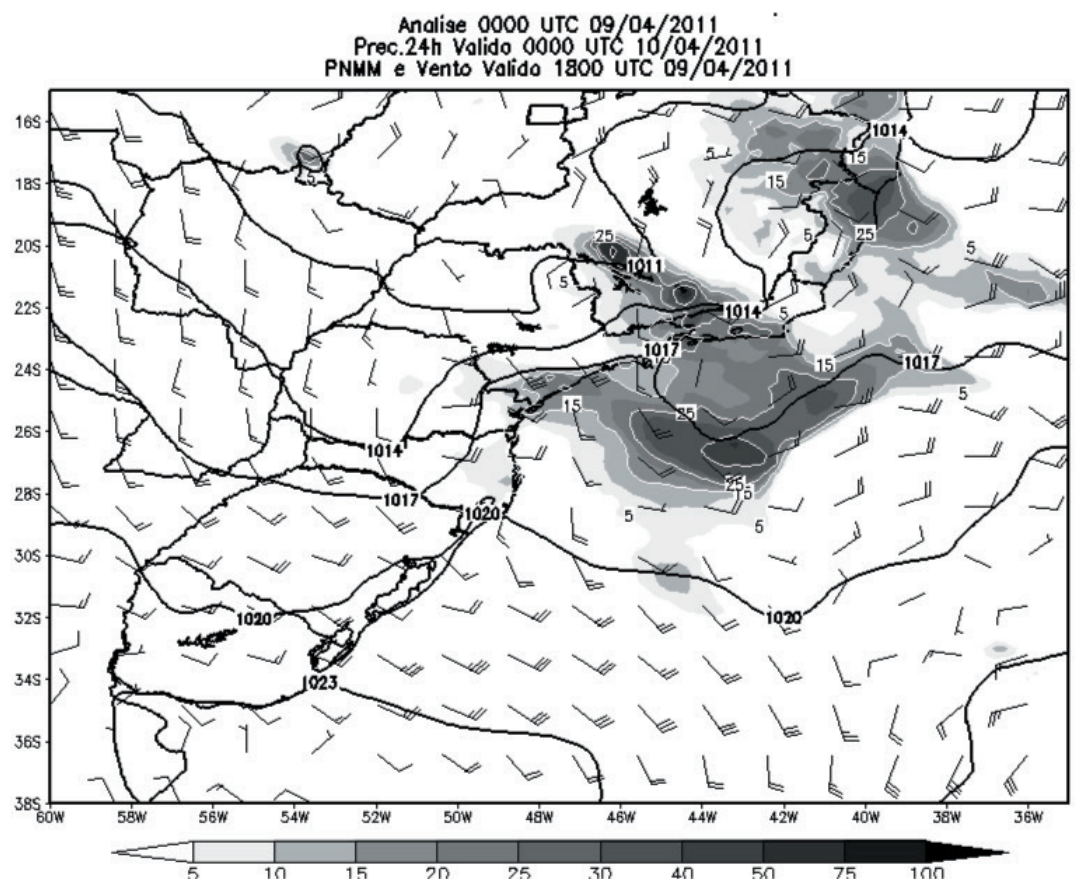

Figura 7 - Precipitação acumulada em 24 horas (entre 00 UTC dos dias 09 e 10/04/2012); vento em superfície e campo de pressão ao nivel médio do mar para às 18 UTC de 09/04, inicializada às 00 UTC de 09/04/2011.

instável. Na rotina operacional, não é raro observar amostras de sondagens com perfis instáveis e incapazes de gerar precipitação convectiva. Situações como esta podem acontecer quando a subsidência, gerada pela presença de uma circulação de alta pressão, tem um peso maior do que a instabilidade de uma parcela de ar. Este aspecto ressalta a importância da interpretação correta dos índices de instabilidade para a qualidade das previsões de tempo.

\section{COMENTÁRIOS FINAIS E CONCLUSÕES}

Neste estudo discutiu-se a viabilidade de se empregar uma ferramenta objetiva para a previsão de tempo, utilizando recursos disponíveis em um ambiente operacional. A metodologia proposta neste trabalho foi desenvolvida com o objetivo principal de auxiliar a rotina do meteorologista previsor, visando prioritariamente a objetividade e a eficiência da ferramenta para a previsão de eventos convectivos. Os critérios utilizados foram desenvolvidos a partir da combinação de índices de instabilidade conhecidos na literatura, enquanto os limiares foram escolhidos arbitrariamente, baseados nas experiências vividas pelos meteorologistas previsores do CPTEC/INPE.

As cartas geradas pela ferramenta operacional, derivadas de saídas do modelo regional ETA/CPTEC, foram analisadas para três situações meteorológicas distintas. No caso 1, as tormentas que atingiram parte da Argentina puderam ser identificadas pela carta tempestade, que indicou qualitativamente a região de maior severidade. Nesta carta foram inclusos elementos importantes para a convecção severa, como a disponibilidade de umidade nas camadas baixas e médias da troposfera, movimento ascendente em $500 \mathrm{hPa}$ e valores relevantes dos índices K e TTS. Resultados semelhantes foram encontrados utilizando a carta pancadas de chuva com trovoadas, que adota os mesmos critérios da carta anterior, porém com limiares menos restritivos. A visualização simples destas cartas permitiu localizar a área mais atingida pelas tempestades com prazo de 48 horas.

Uma alternativa para identificação de regiões com potencial para provocar granizo também foi discutida neste estudo. Alguns parâmetros convectivos importantes para a ocorrência de granizo foram reunidos em uma única carta, como índice de instabilidade SWEAT, que inclui informações sobre o cisalhamento vertical do vento entre a camada baixa e média. Em relação ao caso 2, os resultados mostraram que a ferramenta objetiva foi capaz de representar a ampla área onde houve a ocorrência localizada de granizo. Deve-se ter em mente que a localização exata da precipitação de granizo é possível apenas através de softwares, que utilizam radares meteorológicos para o rastreamento de tempestades com o prazo de poucas horas (ou minutos). Estes aspectos não foram discutidos neste trabalho, podendo ser encontrados nos estudos de Aydin et al. (1986) e de Dixon et al. (1993). Análises de casos, publicados no site do CPTEC/INPE, mostram que tempestades de granizo também podem ocorrer sob uma atmosfera barotrópica ou num 


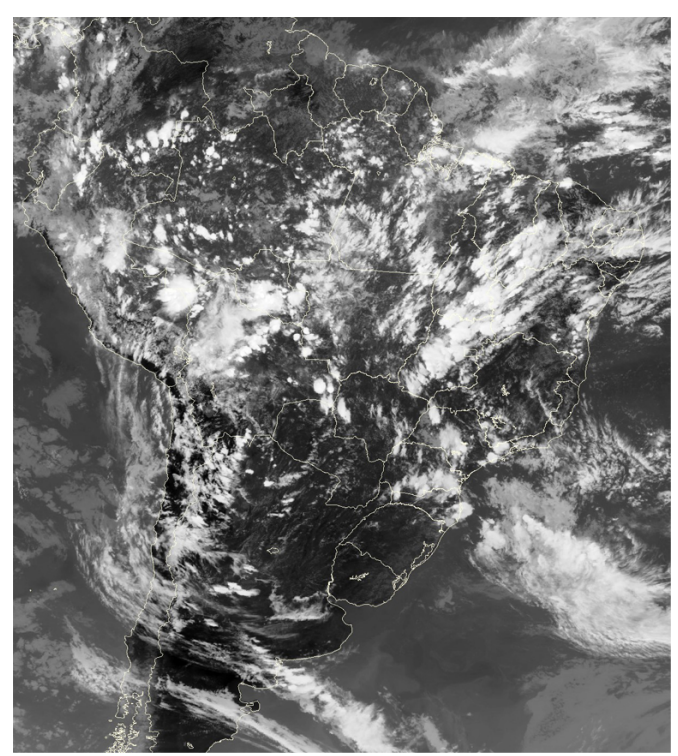

(a)

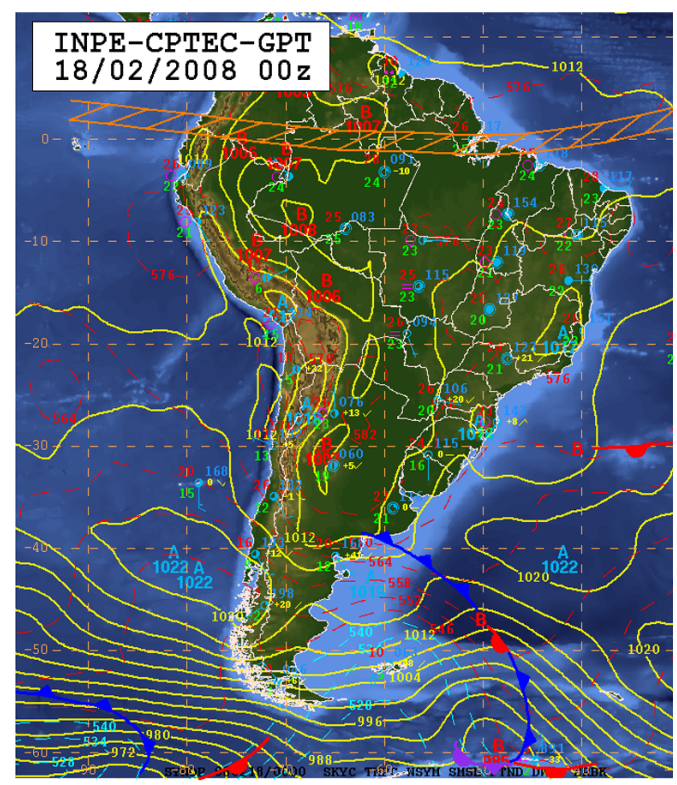

(c)

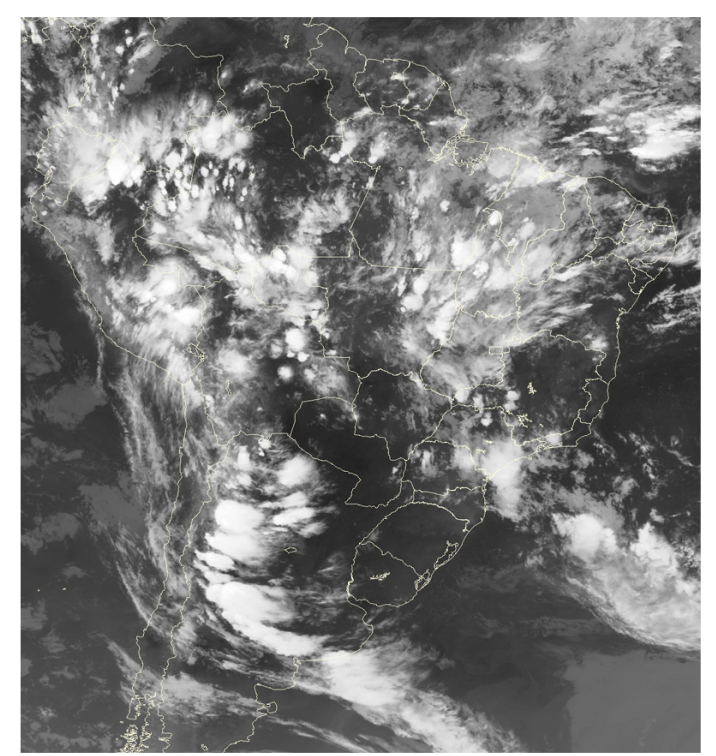

(b)

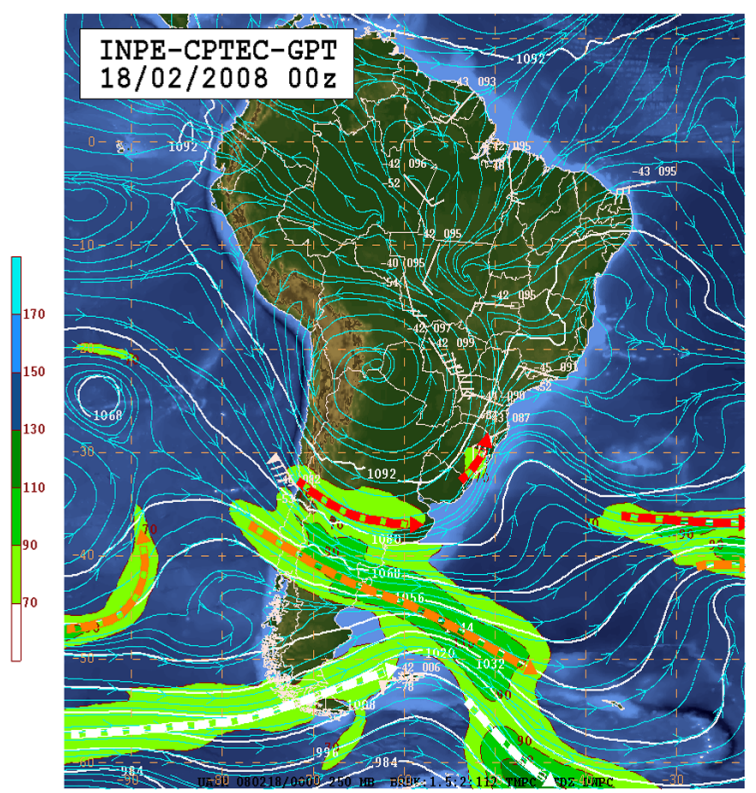

(d)

Figura 8 - Imagens do satélite GOES-12 no canal infravermelho para (a) 18 UTC e (b) 23:45 UTC do dia 17/02/2008. Cartas sinóticas de (c) superfície e de (d) 250hPa para 00 UTC de 18/02/2008.

ambiente desprovido de cisalhamento vertical. Tais eventos são fenômenos isolados e quase sempre estão associados com a instabilidade atmosférica gerada por forçantes locais, sendo muito difícil a sua previsão.

$\mathrm{Na}$ mesma direção dos esforços realizados para estabelecer métodos adequados para previsão de tempo severo, foi proposto um critério capaz de identificar outros tipos de precipitação. A carta pancadas por calor e umidade foi desenvolvida com a finalidade de localizar precipitação do tipo convectiva, porém não necessariamente intensa, sendo muito útil para as situações onde a componente termodinâmica tem um papel relevante para a produção das chuvas. Os resultados mostraram, para um padrão típico de verão na América do Sul (caso 3), uma razoável correspondência entre as áreas de chuva e a distribuição espacial dos índices utilizados na carta pancadas por calor e umidade.

A implementação desta ferramenta na rotina operacional do CPTEC/INPE tem auxiliado a previsão de tempo. 


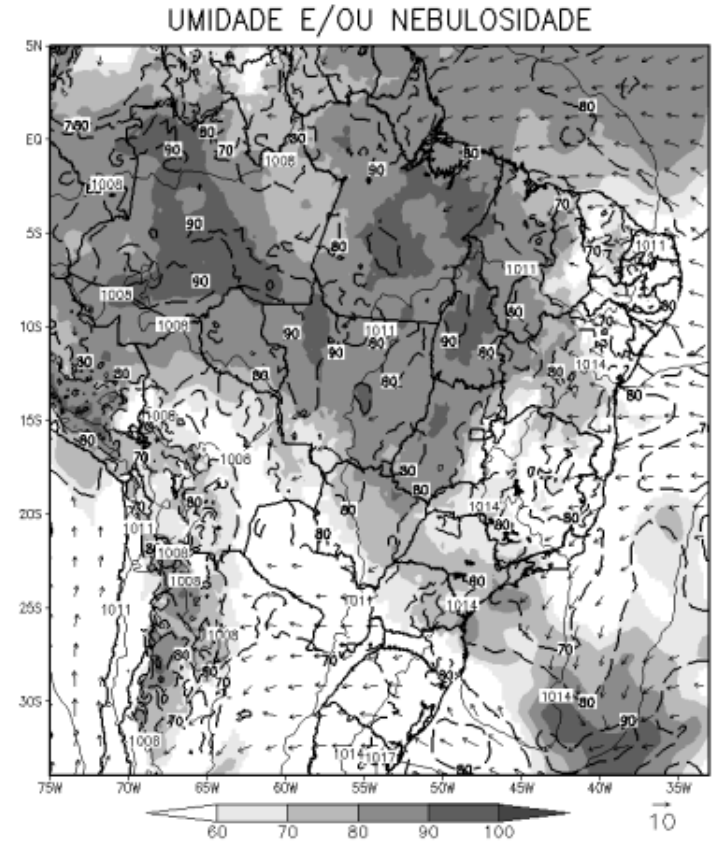

(a)

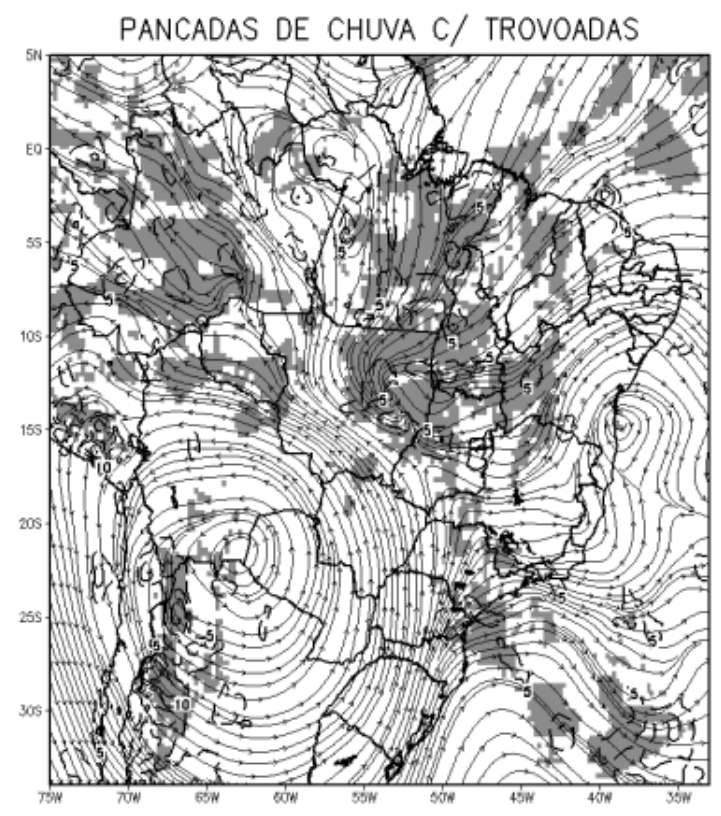

(c)

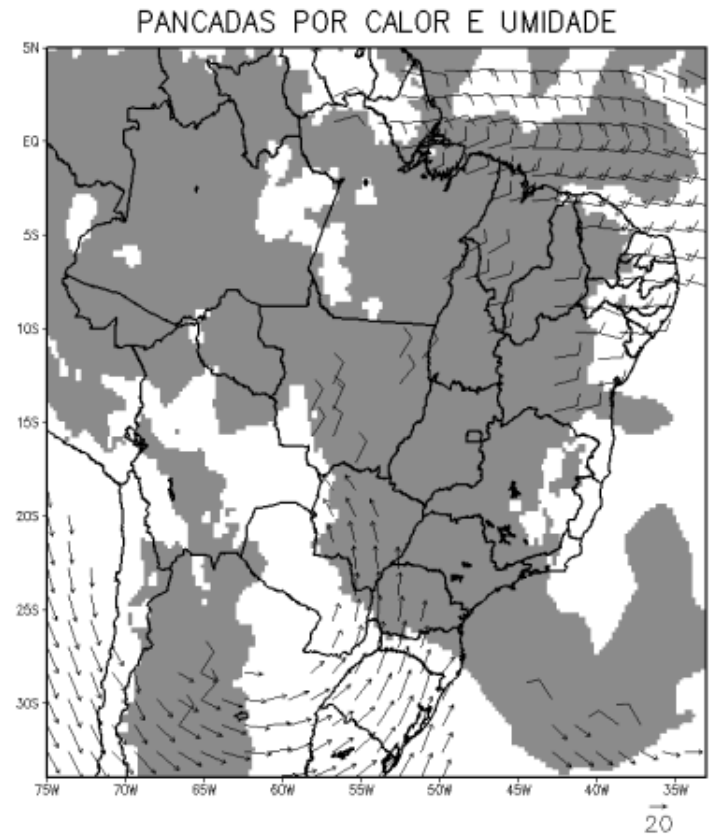

(b)

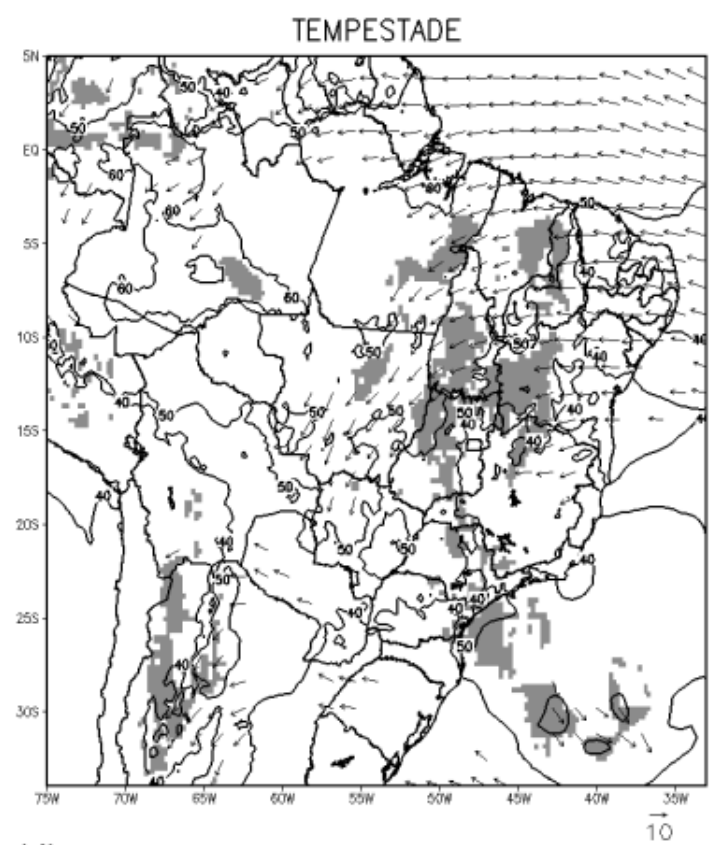

(d)

Figura 9 - Cartas geradas pela análise do modelo ETA para 00 UTC de 18/02/2008: (a) umidade e/ou nebulosidade, (b) pancadas de chuva por calor e umidade, (c) pancadas de chuva com trovoadas e (d) tempestade.

Entretanto, alguns aspectos merecem maior atenção. Deve-se ter em mente que a maioria dos índices de instabilidade representa uma combinação mais ou menos aleatória de medidas meteorológicas (Doswell e Schultz, 2006). Os limiares estabelecidos na literatura nem sempre traduzem o mesmo tipo de precipitação ou fenômeno meteorológico, ou seja, a complexidade da atmosfera impossibilita compilar suas características em números fixos. Estas dificuldades foram discutidas por Nascimento (2005), que sugere não haver números mágicos para a previsão de eventos severos. A experiência operacional dos autores do presente estudo ainda sugere que alguns limiares usados para representar eventos 


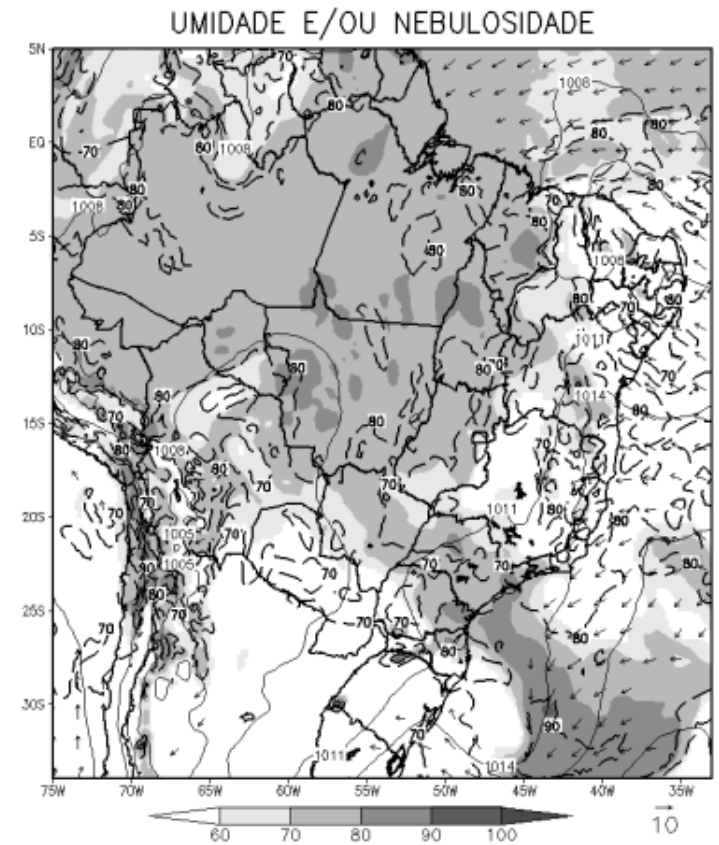

(a)

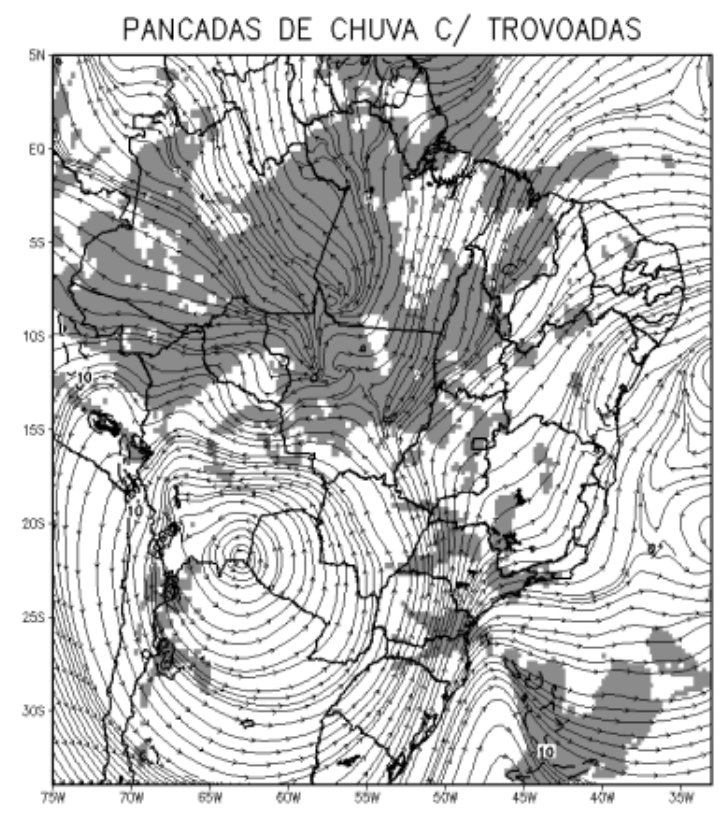

(c)

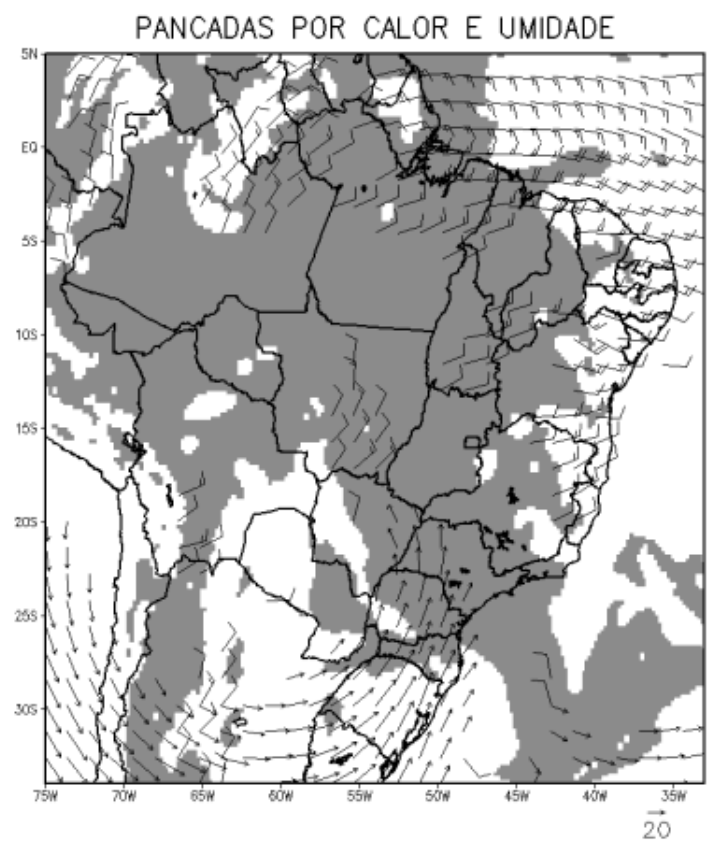

(b)

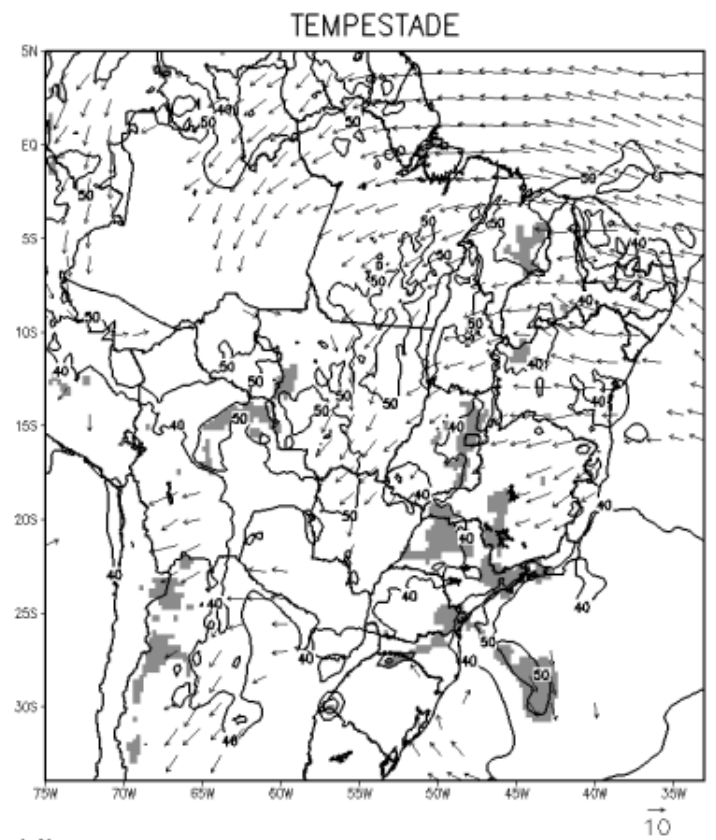

(d)

Figura 10 - Cartas previstas pelo modelo ETA com 24 horas para 00 UTC de 18/02/2008: (a) umidade e/ou nebulosidade, (b) pancadas de chuva por calor e umidade, (c) pancadas de chuva com trovoadas e (d) tempestade.

convectivos podem variar com a geografia do local, período do ano e situação meteorológica.

Outro ponto importante que merece ser mencionado refere-se à qualidade dos perfis atmosféricos previstos pelos modelos numéricos, pois a representatividade do ambiente convectivo dependerá naturalmente da destreza do modelo em reproduzir as características termodinâmicas do local. Talvez mais importante do que estabelecer limiares específicos aos parâmetros convectivos, seja conhecer o comportamento dos modelos sob diferentes situações meteorológicas e, portanto, empregar tais informações à tomada de decisão. Se por um lado estes aspectos põem em dúvida a existência de limiares ideais 


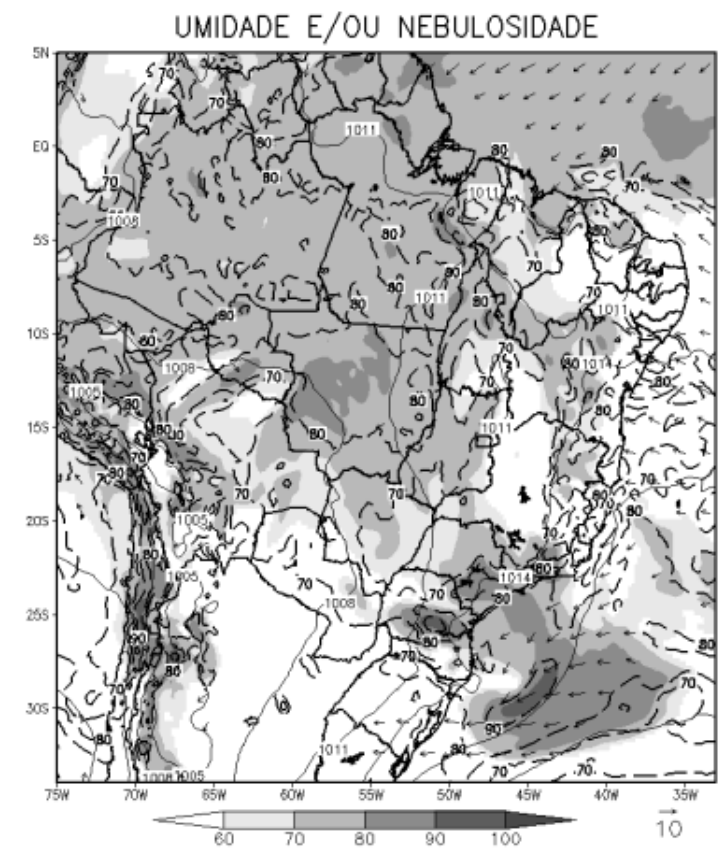

(a)

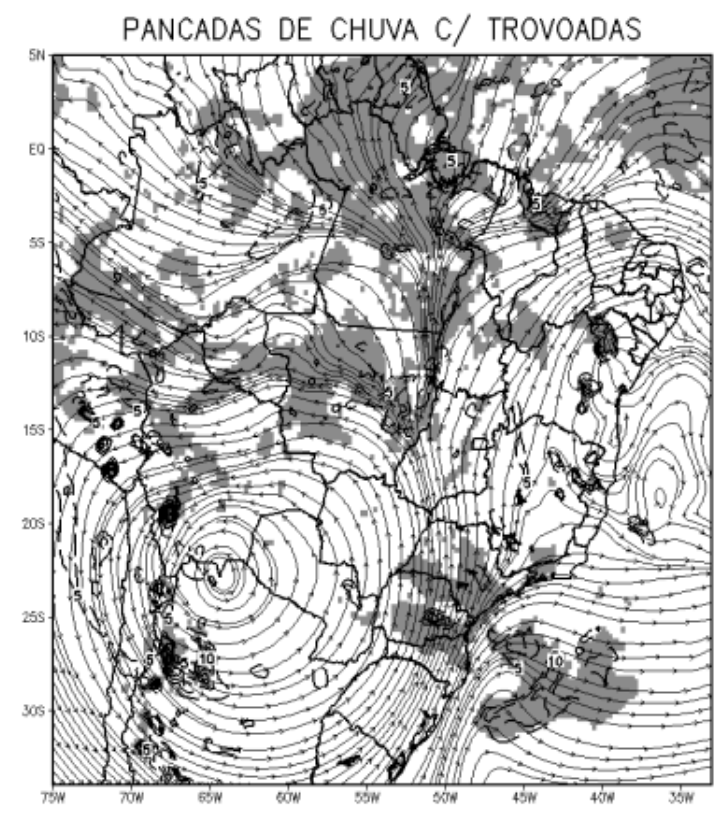

(c)

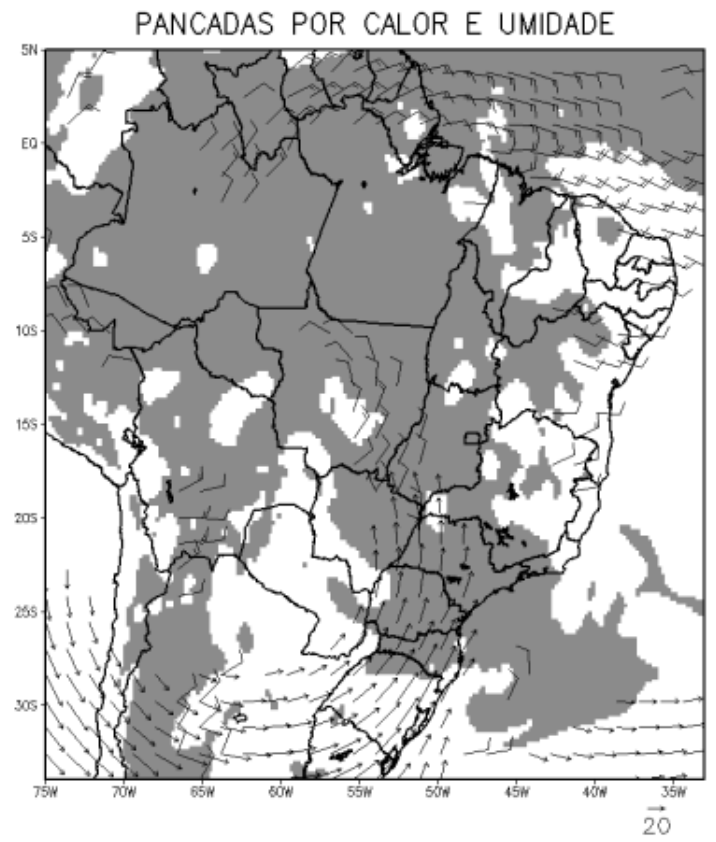

(b)

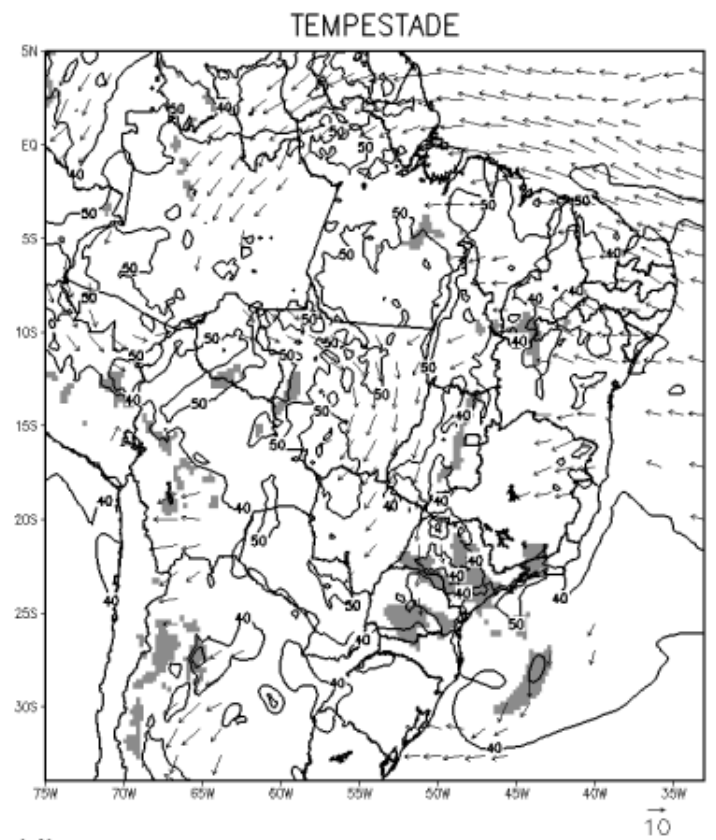

(d)

Figura 11 - Cartas previstas pelo modelo ETA com 48 horas para 00 UTC de 18/02/2008: (a) umidade e/ou nebulosidade, (b) pancadas de chuva por calor e umidade, (c) pancadas de chuva com trovoadas e (d) tempestade.

para o prognóstico de eventos severos, por outro reforçam a importância da componente humana para a previsão destes eventos.

É natural imaginar que a qualidade da previsão de tempo mediante a interpretação visual da ferramenta objetiva dependerá das saídas do modelo numérico. No presente estudo, os limiares atribuídos a cada parâmetro foram baseados no comportamento observado do modelo ETA $20 \mathrm{~km}$. As experiências vividas dentro do ambiente operacional sugerem haver diferenças na distribuição dos parâmetros convectivos produzidos por cada modelo numérico. Esse aspecto não exclui a possibilidade de usar a saída de outro modelo numérico na 
ferramenta objetiva. Entretanto, a escolha pelo uso de outra fonte de dado estará sujeita a alterações nos limiares com a finalidade de ajustá-los devido à possíveis mudanças na distribuição e comportamento dos parâmetros convectivos. As dificuldades encontradas para avaliar a contribuição dos índices de instabilidade, para o desenvolvimento dos sistemas convectivos, geram incertezas e subjetividade à previsão de tempo (severo ou não). Portanto, a qualidade dos prognósticos dependerá da habilidade do meteorologista previsor em julgar de forma correta as condições futuras, utilizando para isso a sua experiência e todos os recursos disponíveis em um ambiente operacional. Embora a ferramenta proposta neste estudo seja objetiva, a sua interpretação tem um caráter subjetivo e é influenciável pela opinião do meteorologista que avalia os seus resultados. Neste sentido, o hábito da realização rotineira de uma análise sinótica é uma prática que possibilita certificar-se da existência de situações atmosféricas favoráveis à ocorrência de tempestades severas, permitindo eventualmente antecipar-se em alguns dias à identificação de eventos meteorológicos adversos, assim como reduzir a possibilidade da emissão de alarmes falsos. Este estudo não se propôs investigar a existência de modelos conceituais para tempestades severas na América do Sul, nem tampouco apresentar técnicas para previsão de tempo à curto prazo, porém alguns aspectos relacionados a esta última podem ser encontrados em Silva Dias (1987) e Nascimento (2005).

Para concluir, fica a pergunta se a ferramenta objetiva proposta neste estudo seria uma alternativa viável para a previsão de tempo no Brasil, onde existem Regiões com diferentes características e regimes de precipitação? Como foi discutido neste estudo, a complexidade dos sistemas convectivos impossibilita incorporar todas as suas características através de indicadores atmosféricos. Entretanto, a aplicação desta técnica combinada à experiência do meteorologista tem representado uma tática eficiente para a identificação rápida das regiões favoráveis à ocorrência de tempo severo. A implementação desse método na rotina operacional pretende suprir algumas limitações dos modelos numéricos, principalmente no que se refere à localização e intensidade da precipitação. É importante deixar claro que os limiares foram ajustados a partir da necessidade operacional, sem uma verificação climatológica e específica para cada localidade. Trabalhos futuros deverão ser realizados com o intuito de corroborar estatisticamente a validade de cada critério proposto em discriminar diferentes ambientes convectivos. Para isso é desejável a utilização de dados de observações obtidos diretamente de radiossondagens.

\section{REFERÊNCIAS}

ANDRADE, K. M. et al. Avaliação qualitativa do desempenho da ferramenta objetiva de previsão de tempo utilizada no ambiente operacional do CPTEC/INPE para um caso de evento severo. In: Anais do XVI Congresso Brasileiro de Meteorologia, 2010, Belém-PA. Disponível em: http:/urlib. net/8JMKD3MGP7W/37UG4RB. Acesso em: 09 ago. 2012.

AYDIN, K.; SELIGA, T. A.; BALAJI, V. Remote sensing of hail with a dual linear polarization radar. Journal of Climate and Applied Meteorology.,v. 25, p. 1475-1484, 1986.

BENETI, C. A.; SILVA DIAS, M. A. Análise da performance de índices de instabilidade como previsores de tempestades na região de São Paulo. In: Anais do IV Congresso Brasileiro de Meteorologia, Brasília-DF, Sociedade Brasileira de Meteorologia, v.2, p. 65-70, 1986.

BERBERY, H.; COLLINI, E.: Springtime precipitation and water vapor flux over southeastern South America. Monthly Weather. Review, v. 128, p. 1328-1346, 2000.

BLACK, T. L. The new NMC mesoscale Eta Model: Description and forecast examples. Weather and Forecasting, v. 9, p. 265-278, 1994.

BLUESTEIN, H. Synoptic-Dynamic Meteorology in Midlatitudes Vol. II - Observation and Theory of Weather Systems. New York: Oxford University Press, p. 594, 1993.

BRIMELOW, J. C.; KRAUSS, T.; REUTER, G. W. Operational forecasts of maximum hailstone diameter in Mendoza, Argentina. Journal of Weather Modification, v. 34, p. 8-17, 2002.

BROOKS, H. E.; LEE, J. W.; CRAVEN, J. P. The spatial distribution of severe thunderstorm and tornado environments from global reanalysis data. Atmospheric Research, v. $67-$ 68, p. 73-94, 2003.

DEHENAUW, D.: An objective hail size forecasting method based on mesoscale model output. Scientific publication, Royal Meteorological Institute of Belgium, 2003. Disponível em: www.kmi.be/meteo/download/de/519779/ pdf/rmi_scpub-022.pdf. Acesso em 10 dez. 2012.

DIXON, M.; WIENER, G. TITAN. Thunderstorm Identification, Tracking, Analysis, and Nowcasting-A Radar-based Methodology. Journal of Atmospheric and Oceanic Technology, v. 10, p. 785-797, 1993.

DOSWELL, C.A. III; SCHULTZ, D.M. On the use of indices and parameters in forecasting severe storms. Electronic Journal of Severe Storms Meteorology, v. 1(3), p. 1-22, 2006.

ESCOBAR, G. C. J.; ANDRADE, K. M. Climatologia dos índices de instabilidade K e Total Totals (TT) para o Sul e Sudeste do Brasil. In: Anais do XVI Congresso Brasileiro de Meteorologia, 2010, Belém-PA. Disponível em: http:// www.cbmet2010.com/anais/artigos/682_79683.pdf. Acesso em 15 jul. 2013.

ESCOBAR, G. C. J.; SILVA, P. E. D. Análise sinótica e avaliação qualitativa do desempenho da ferramenta objetiva 
de previsão de tempo utilizada no ambiente operacional do CPTEC/INPE para um caso de evento severo ocorrido na cidade de Rosário (Argentina). In: XII Congresso Latino Americano e Iberico de Meteorologia. In: Anais do X Congresso Argentino de Meteorologia, Buenos Aires, AR. 2009. Disponível em: <http://mtc-m19.sid.inpe.br/ rep/sid.inpe.br/mtc-m19@80/2009/12.07.13.09>.Acesso em 01 jul. 2011.

ESCOBAR, G. C. J; SILVA, V. Análise sinótica e previsibilidade de um evento extremo ocorrido nas Regiões Sul e Sudeste do Brasil durante o mês de abril de 2011. In: Anais do XVII Congresso Brasileiro de Meteorologia, 2012, Gramado, RS. Disponível em: http://www.cbmet2012.com/anais/ pdfs/62GS.pdf. Acesso em: 10 set. 2012.

FOGACCIA, C. V. C.; PEREIRA FILHO, A. J. Turbulência e cisalhamento do vento na área do Aeroporto Internacional de São Paulo/Guarulhos. In: Anais do XII Congresso Brasileiro de Meteorologia, Foz do Iguaçu/PR, Sociedade Brasileira de Meteorologia, em mídia digital, 2002.

FUJITA T.T. Objectives, operation and results of project NIMROD. Preprints, 11th Conference on Severe Local Storms, Kansas City, MO, Amer. Met. Soc., p. 259-266, 1979.

FUJITA, T. T. Tornadoes around the world. Weatherwise, v. 26, p. 56-62, 1973.

GALWAY, J. G. The lifted index as a predictor of latent instability. Bulletin of the American Meteorological Society, v. 43, p. 528-529, 1956.

GAN, M. A.; KOUSKY, V. E.; ROPELEWSKI, C. F. The South America Monsoon Circulation and Its Relationship to Rainfall over West-Central Brazil. Journal of Climate, v. 17, p. 47-66, 2004.

GEORGE, J. J. Weather Forecasting for Aeronautics. Academic Press, p. 673, 1960.

GUEDES, R. L.; SILVA DIAS, M. A. F. Estudo de tempestades severas associadas com o jato subtropical na América do Sul. In: Anais do III Congresso Brasileiro de Meteorologia, Belo Horizonte-MG, Soc. Bras. Meteorologia, v. 2, p. 289296, 1984.

HALLAK, R.; PEREIRA FILHO, A. J. Análise do desempenho de índices de instabilidade atmosférica na previsão de fenômenos convectivos de mesoescala na região metropolitana de São Paulo entre 28 de janeiro e 04 de fevereiro de 2004. Revista Brasileira de Meteorologia, v. 27, n.2, p. 173-206, 2012.

HENRY, W. The Skew-T, Log P Diagram. National Weather Service Training Center, EUA, p. 68, 1987.

HOUZE, R. A. Cloud Dynamics. Academic Press, p. 573, 1993. JANJIC, Z. I. The Step-Mountain Eta Coordinate Model: further Developments of the Convection, Viscous Sublayer, and
Turbulence Closure Schemes. Monthly Weather Review, v.122, n.5, p.927-945, 1994.

JOE, P. et al. The S2K severe weather detection algorithms and their performance. Weather and Forecasting, v.19, p. 43-63, 2004.

JOHNS, R. H.; DOSWELL III, C. A. Severe local storms forecasting. Weather and Forecasting, v. 7, p. 588-612, 1992.

KODAMA, Y. M. Large-scale common features of subtropical precipitation zones (the Baiu frontal zone, the SPCZ, and the SACZ). Part I: Characteristics of subtropical frontal zones. Journal of Meteorological Society of Japan., v. 70, p. 813-835, 1992.

MACHADO, L. A. T.; LAURENT, H. The convective system area expansion over Amazonia and its relationships with convective system life duration and high-level wind divergence. Monthly Weather Review, v. 132, p. 714-725, 2004.

MARCELINO, I. P. V. O.; FERREIRA, N. J.; CONFORTE, J. C. Análise do episódio de tornado ocorrido no dia 07/02/98 no município de Abdon Batista - SC. In: Anais do XI Simpósio Brasileiro de Sensoriamento Remoto, Belo Horizonte, 2003. Anais... São José dos Campos: INPE, p. 5-10, 2003.

MARCELINO, I. P. V. O.; HERRMANN, M. L. P.; FERREIRA, N. J. The Occurrence of Tornadoes in Santa Catarina State, Brazil. Boletim da Sociedade Brasileira de Meteorologia, v. 33, n.1, 2009.

MARCELINO, I. P. V. O.; MENDONÇA, M.; RUDORFF, F. M. Ocorrências de granizo no Estado de Santa Catarina. In: Anais do I Simpósio Brasileiro de Desastres Naturais, Florianópolis/SC, UFSC, em mídia digital, 2004.

MARENGO, J. A. et al. The South American low-level jet east of the Andes during the 1999 LBATRMM and LBA-WET AMC campaign. Journal of Geophysical Research, v. 107, p. 8079, 2002.

MENEZES, W. F. et al. A study of simulated instability indices and its behavior over Rio de Janeiro, In: Anais do Proceedings of 8 ICSHMO, Foz Do Iguaçu, Brazil, INPE, p. 1849-1955, 2006.

MESINGER F. A blocking for representation of mountains in atmospheric models. Rivista di Meteorologia Aeronautica, v.44, n. 1-4, p.195-202, 1984.

MESINGER F. et al. The step-mountain coordinate: model description and performance for cases of Alpine lee cyclogenesis and for a case of Appalachian redevelopment. Monthly Weather Review, v. 116, p. 1493-1518, 1988.

MILLER, R. C. Notes on analysis and severe storm forecasting procedures of the Air Force Global Weather Central. Volume 200 of Technical Report, Air Weather Service, United States Air Force, p. 190, 1972. 
MILlS, G. A.; COLQUHOUN, J. R. Objective prediction of severe thunderstorm environments: preliminary results linking a decision tree with an operational regional NWP model. Weather and Forecasting, v. 13, p. 1078-1092, 1998.

MOORE, J. T.; PINO, J. P. An interactive method for estimating maximum hailstone size from forecast soundings. Weather and Forecasting, v. 5, p. 508-526, 1990.

MORRISON, I.; BUSINGER, S. Synoptic structure and evolution of a Kona low. Weather and Forecasting, v. 16, p. 81-98, 2001.

MOURA, R. G et al. Avaliação do modelo regional ETA utilizando as análises do CPTEC e NCEP. Revista Brasileira de Meteorologia, v. 25, n. 1, p. 46-53, 2010.

NASCIMENTO, E. L. Previsão de tempestades severas utilizandose parâmetros convectivos e modelos de mesoescala: Uma estratégia operacional adotável no Brasil? Revista Brasileira de Meteorologia, v.20, n.1, p.121-140, 2005.

NASCIMENTO, E. L.; FOSS, M. A 12-yr climatology of severe weather parameters and associated synoptic pattern for subtropical South America. Conference on Severe Local Storms, 2010. Disponível em https://ams.confex.com/ams/ pdfpapers/175790.pdf. Acesso em: 15 jul. 2013.

NOGUÉS-PAEGLE, J. A comparative review of South American low level jets. Meteorologica, v. 3, p.73-82, 1998.

NOGUÉS-PAEGLE, J.; MO, K. C. Alternating wet and dry conditions over South America during summer. Monthly Weather Review, v. 125, p. 279-291, 1997.

OLIVEIRA, F. P.; OYAMA, M. D. Radiosounding-derived convective parameters for the Alcântara Launch Center. Journal of Aerospace Technology and Management. v. 2, p. 211-216, 2009.

OTKIN, J. A.; MARTIN, J. E. A Synoptic Climatology of the Subtropical Kona Storm. Monthly Weather Review, v. 132, n. 6, p. 1502-1517, 2004.

QUADRO, M. F. L. Estudos de episódios de Zona de Convergência do Atlântico Sul (ZCAS) sobre a América do Sul. 1994. 97f. (INPE-6341-TDI/593). Dissertação (Mestrado em Meteorologia) - Instituto Nacional de Pesquisas Espaciais, São José dos Campos, 1994.

SALIO, P.; NICOLINI, M.; ZIPSER, E. J. Mesoscale convective systems over southeastern South America and their relationship with the South American low-level jet. Monthly Weather Review, vol. 135, n. 4, p. 1290-1309, 2007.
SANTOS E SILVA, C. M.; SILVA, F. R.; LEME, N. M. P. Ciclo anual de precipitação como função de índices de instabilidade termodinâmica e fluxos de energia estática: análises em Maxaranguape-RN, Revista Brasileira de Meteorologia, v. 26, n. 2, p. 235-242, 2011.

SAULO, C.; NICOLINI, M.; CHOU, S. C. Model characterization of the South American low-level flow during the 1997-1998 spring-summer season. Climate Dynamics, v. 16, p. 867-881, 2000.

SCHWARZKOPF, M. L. Severe storms and tornadoes in Argentina. In: Preprints, 12th Conference on Severe Local Storms, San Antonio, EUA, American Meteorological Society, p.59-62, 1982.

SILVA DIAS, M. A. F. Sistemas de mesoescala e previsão de tempo a curto prazo. Revista Brasileira de Meteorologia, v. 2, p. 133- 150, 1987.

SILVA DIAS, M. A. F. An Increase in the Number of Tornado Reports in Brazil. Weather Climate and Society, v. 3, p. 209-217, 2011.

SILVA DIAS, M. A. F. Índices de instabilidade para a previsão de chuva e tempestade severas. Universidade de São Paulo, SP, 2000. Disponível em: <http:/master.iag.usp.br/ensino>. Acesso em: 25/07/2012.

SILVA DIAS, M. A. F.; GRAMMELSBACHER, E. A. A possível ocorrência de um tornado em São Paulo no dia 26 de abril de 1991: um estudo de caso. Revista Brasileira de Meteorologia, v. 6, p. 513-522, 1991.

TEIXEIRA, M. S.; SATYAMURTY, P. Dynamical and synoptic characteristics of heavy rainfall episodes in southern Brazil. Monthly Weather Review, v. 135, p. 598-617, 2007.

VELASCO, I.; FRITSCH, J. M. Mesoscale convective complexes in the Americas. Journal of Geophysical Research, v. 92 (D8), p. 9591-9613, 1987.

WAKIMOTO, R. M. Convectively Driven High Wind Events. Meteorological Monographs, v. 28,p.255-298, 2001. Disponível em: < http://dx.doi.org/10.1175/0065-940128.50.255>. Acesso em 23 jul. 2013.

WITT, A. et al. An enhanced hail detection algorithm for the WSR-88D. Weather and Forecasting, v. 13, p. 286-303, 1998.

ZIPSER, E. J. et al. Where are the most intense thunderstorms on earth? Bulletin of the American Meteorological Society, v. 87 , p. 1057-1071, 2006. 